Cite this: Nat. Prod. Rep., 2013, 30, 1299

\section{Targeting heat-shock-protein 90 (Hsp90) by natural products: geldanamycin, a show case in cancer therapy}

\author{
Jana Franke, ${ }^{a}$ Simone Eichner, ${ }^{a}$ Carsten Zeilinger ${ }^{\star b}$ and Andreas Kirschning ${ }^{* a}$
}

Covering: 2005 to 2013

In this review recent progress in the development of heat shock proteins (Hsp90) in oncogenesis is illuminated. Particular emphasis is put on inhibitors such as geldanamycin and analogues that serve as a natural product show case. Hsp90 has emerged as an important target in cancer therapy and/or against pathogenic cells which elicit abnormal Hsp patterns. Competition for ATP by geldanamycin and related compounds abrogate the chaperone function of Hsp90. In this context, this account pursues three topics in detail: a) Hsp90 and its biochemistry, b) Hsp90 and its role in oncogenesis and c) strategies to create compound libraries of structurally complex inhibitors like geldanamycin on which SAR studies and the development of drugs that are currently in different stages of clinical testing rely.

www.rsc.org/npr

5.4.2 Blocking of selected enzymes by genetic engineering

5.4.3 Mutasynthetic approaches

6 Assaying inhibitory effects on Hsp90 function by high throughput screening

7 Outlook

8 Acknowledgements

$9 \quad$ Notes and references

\section{Introduction}

Cancer is still a leading cause of death worldwide with a mortality rate of around 13\% in 2008 and general therapies are far from being a reality yet. ${ }^{1}$ It has been shown that cancer can originate from an excessive function of proteins or chaperone associated protein misfolding. ${ }^{2}$ Misfolded proteins may trigger loss of normal functions and lead to deregulated physiological functions in cells. The function of molecular chaperones is to maintain the proper folding of proteins, which is important in cellular homeostasis to keep the balance between protein synthesis and degradation. Heat shock proteins (Hsps) belong to a family of molecular chaperones of which Hsp90, a highly conserved $90 \mathrm{kDa}$ protein, is the most abundant eukaryotic heat shock protein, but it is also found in bacteria (HtpG). ${ }^{3}$ Generally, binding of natural ligands, such as adenine nucleotides (ATP/ADP), co-chaperones, and client proteins can alter the conformation of Hsp90. ${ }^{4}$ A series of small molecules, in particular natural products, have been identified to compete for different binding sites of natural Hsp90, thus inhibiting its chaperone function. The most famous example is probably the ansamycin antibiotic geldanamycin $\mathbf{1}$ as well as related secondary metabolites like herbimycin 2 and macbecin 3 (both 
quinone and hydroquinone forms exist) and the phenolic metabolite reblastatin (5) (Fig. 1). ${ }^{5}$ Also autolytimycin (4) was isolated in the early 2000s, both from Streptomyces sp. S6699 as well as from a culture broth of Streptomyces autolyticus JX-47 from which its name was derived. ${ }^{6 a}$ Only recently, $\mathrm{Wu}$ and coworkers reported several new metabolites 6-8 from Streptomyces hygroscopicus 17997 , all of which are functionalised at C-19. ${ }^{6 c-e}$

It is important to note that these natural products have paved the way for a deeper understanding of heat shock proteins, and as a result Hsp90 has emerged as a remarkable therapeutic target for the treatment of cancer. In this context the identification of binding sites of the target receptor, such as Hsp90, that significantly affect its function is important. This review is intended to provide an overview and a story on firstly the biochemistry of heat shock protein 90 which will be linked to biomedical and pharmaceutical aspects and options for cancer therapy. Secondly, the preparation of geldanamycin libraries to uncover structure-activity relationship (SAR) knowledge will be discussed in detail as geldanamycin is a showcase for generating libraries by chemical as well as biosynthetic methods.

Thirdly, issues on assaying the inhibition of Hsp90 by geldanamycin (1) will be included in the review, that along with synthetic efforts resulted in "SAR-mapping" of this complex natural product.

\section{Biological aspects of Hsp90 as target in cancer therapy}

\subsection{General and structural aspects of Hsp90}

Hsp90 is highly conserved and it is present in prokaryotes and eukaryotes, with the exception of archaea where only small heat shock proteins exist. ${ }^{9}$ The human heat shock protein 90 (Hsp90 $\alpha$ ) is an 855 aa protein of $98.1 \mathrm{kDa}$, encoded by the Hsp90aa1 gene on chromosome 14, whereas the cytoplasmic

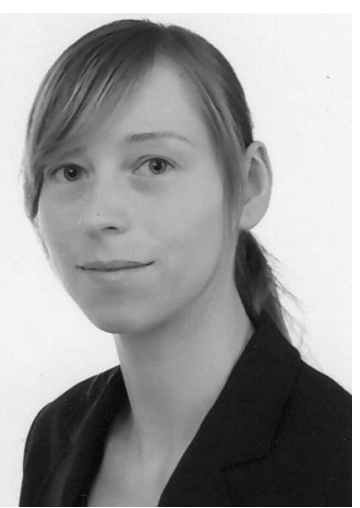

Jana Franke received her diploma in chemistry from the Leibniz University of Hannover in 2010, and was a visiting scholar with Dr Martin D. Smith at Oxford University, UK, in 2009. She is currently pursuing a Ph.D. under the supervision of Prof. Dr Andreas Kirschning at the Leibniz University of Hannover. Her current research is focused on natural product synthesis.

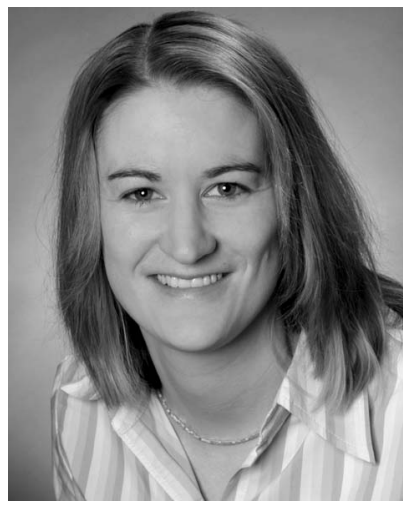
Simone Eichner studied chemistry at the Leibniz University of Hannover. She joined the group of Prof. Andreas. Kirschning and received her PhD in 2011 working in the field of mutasynthesis. Afterwards she joined ratiopharm GmbH where she has worked in chemical research since then.

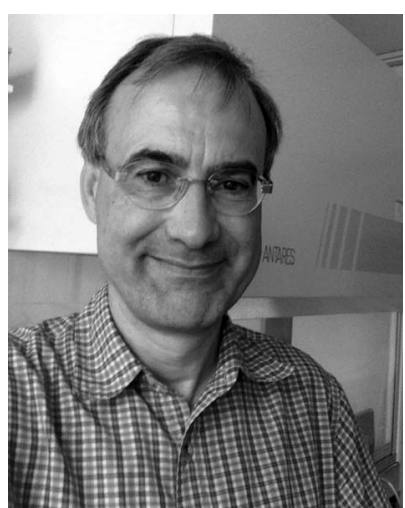

Carsten Zeilinger studied biology at the University of Osnabrück (Germany). In Osnabrück he joined the group of Prof. Elmar W. Weiler and received his $P h D$ in 1990 working in the field of plant physiology. After a postdoctoral stay at the University of Göttingen (Germany) with Prof. $R$. Hedrich he started his independent research at the University of Hannover in 1991, where he finished his habilitation in 1998. His research interests cover membrane proteins and protein folding, temperature effects on protein function and assay design for studying protein function.

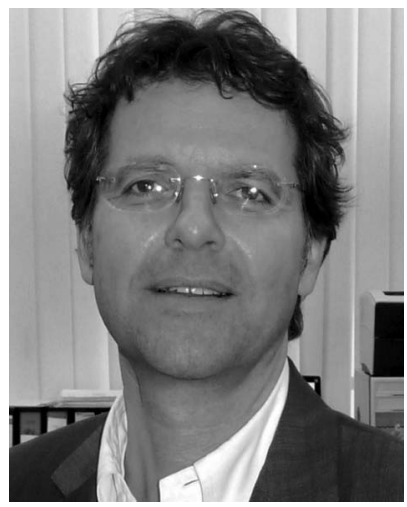

Andreas Kirschning studied chemistry at the University of Hamburg and at Southampton University (UK). In Hamburg, he joined the group of Prof. Ernst Schaumann and received his PhD in 1989 working in the field of organosilicon chemistry. After a postdoctoral stay at the University of Washington (Seattle, USA) with Prof. Heinz G. Floss, he started his independent research at the Clausthal University of Technology in 1991, where he finished his habilitation in 1996. In 2000 he moved to the Leibniz University Hannover. His research interests cover structure elucidation as well as the semi-, total and mutasynthesis of natural products, biomedical biopolymers, and synthetic technologies (solid-phase assisted synthesis, microreactors and inductive heating). 


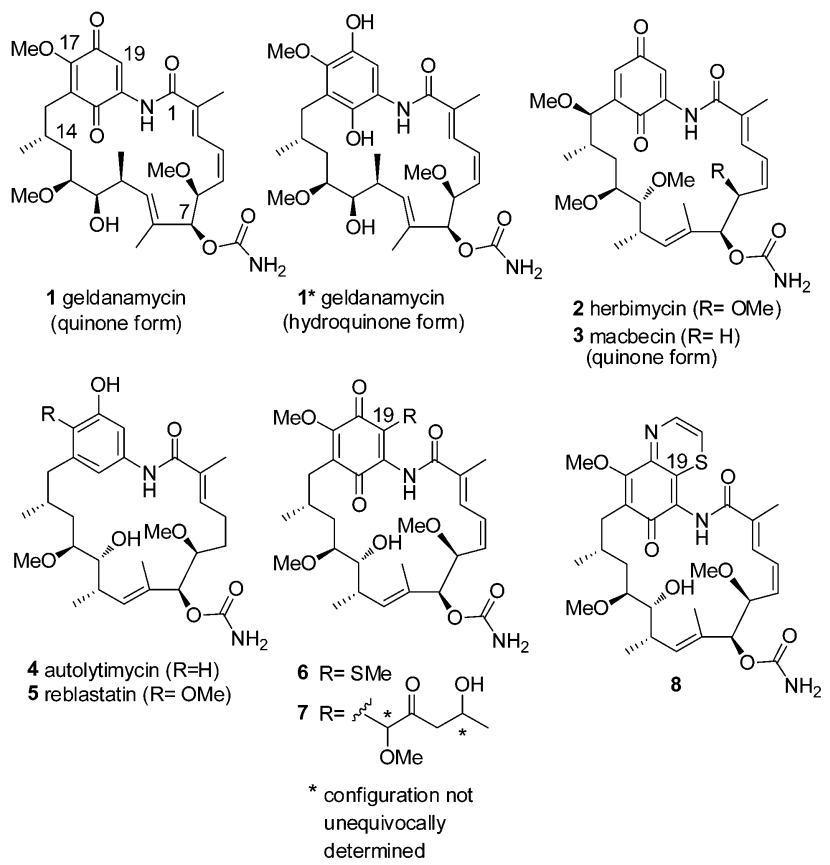

Fig. 1 Structures of ansamycin-based Hsp90 inhibitors 1-8 (the quinone forms e.g. of 1 can be chemically converted into the hydroquinone forms. e.g. $1 *$ ). ${ }^{\mathbf{7}}$

form is a homodimer. Primarily, the heat shock proteins are classified and named by their molecular weight, a newer nomenclature annotates them as HSPC members (with five known genes in the human genome) with HSPC1 for Hsp90, HSPC2 for Hsp90 $\alpha$ and HSPC3 for HSP $\beta .^{10}$ Each monomer consists of four structural domains, the C-terminal (CTD) and $\mathrm{N}$-terminal (NTD) and a middle domain (MD) connected to the NTD through an unstructured linker region. ${ }^{11}$ Hsp90 exists in four different isoforms present in eukaryotic cells and plays a central role in the complex network of cellular functions. ${ }^{12}$ The heat shock protein Hsp90 is part of a huge interactome, formed by co-chaperones, chaperones and clients. ${ }^{13}$

Hsp90 plays a central role and interacts with many other human proteins. Computational approaches such as STRING (search tool for recurring instances of neighbouring genes) were developed to visualise relevant interactome routes, which can also be applied to Hsp90 (Fig. 2). STRING is able to filter data from more than 1000 organisms, 5 million proteins and $>200$ million interactions stored. ${ }^{\mathbf{1 3 a , b}}$ Hits are ranked ( 0 is no and 1 the highest interaction) and the relationship between two genes is presented by lines, whereas strong interactions are monitored

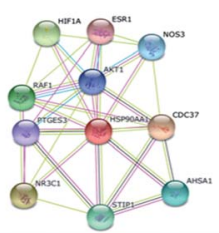

10

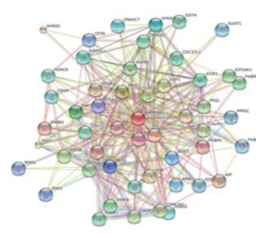

50

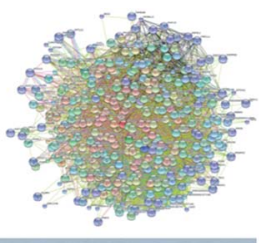

$500 \begin{gathered}\substack{\text { interaction } \\ \text { partner }} \\ 0\end{gathered}$
Fig. 2 A cartoon of the Hsp90 interactome computed by the STRING database. by an increase of line intensities. In Fig. 2, candidates (colored balls) interacting with human Hsp90 (dark red ball) are ordered with respect to 10, 50 and 500 candidates. Eleven high scoring candidates (0.999-0.997) are CDC37, NR3C1, HIF1A, RAF1, STIP1, AHSA1, NOS3, AKT1, PTG/ES3, ESR1, FKBP5, all of which are well-known targets in cancer diagnostics and therapy. This tool finds support by LUMIER (luminescence-based mammalian interactome mapping) an automated HTP technology for the systematic mapping of protein-protein-interaction networks in mammalian cells. ${ }^{\mathbf{1 4}}$

These maps unravel the central physiological role of Hsp90 and direct and indirect contact partners can be identified as part of a huge interactome network that adds up to 600 partners. Clearly, this huge network also demonstrates that all the biological roles and diverse functions of Hsp90 are not yet fully understood and the discussion to follow can only provide a current and incomplete view on Hsp90.

As mentioned above, five human Hsp90 family members are known: a) HSP90AA1 (HSPC1), b) Hsp90 $\alpha$ (HSPC2), c) Hsp90 (HSPC3), d) the glucose-regulated protein 94 (Grp94) (HSPC4), and e) the tumor necrosis factor receptor-associated protein 1 (Trap-1, HSPC5). All members work in a similar fashion, but they do interact with different client proteins. Hsp90 $\alpha$ and Hsp90 $\beta$ are closely related cytoplasmic isoforms. ${ }^{15}$ The expression of Hsp90 $\alpha$ is associated with proliferation of cancer cells and tumor progression, whereas the Hsp90 $\beta$ isoform is related to drug resistance. ${ }^{\mathbf{1 6}}$ The Hsp90 monomer, which in fact is commonly homodimerised, has three functional domains (Fig. 3): a) an N-terminal nucleotide binding domain (NBD, $25 \mathrm{kDa}$ ) which accommodates ATP as well as some Hsp90 inhibitors like geldanamycin (1), b) the middle domain (MD, $55 \mathrm{kDa}$ ) where the docking sites for co-chaperones and client proteins are located and c) the C-terminal domain (CTD, $10 \mathrm{kDa}$ ) with the C-terminal dimerisation domain (CDD). The latter is also able to interact with ATP, co-chaperones and few Hsp90 inhibitors, such as novobiocin (9). ${ }^{\mathbf{1 7}}$ The charged domain between the NBD and CDD serves as a linker region and chaperone activity is established by dimerisation at the CDD domain. Co-chaperones and post-translational modifications of Hsp90 modulate its chaperone activity.

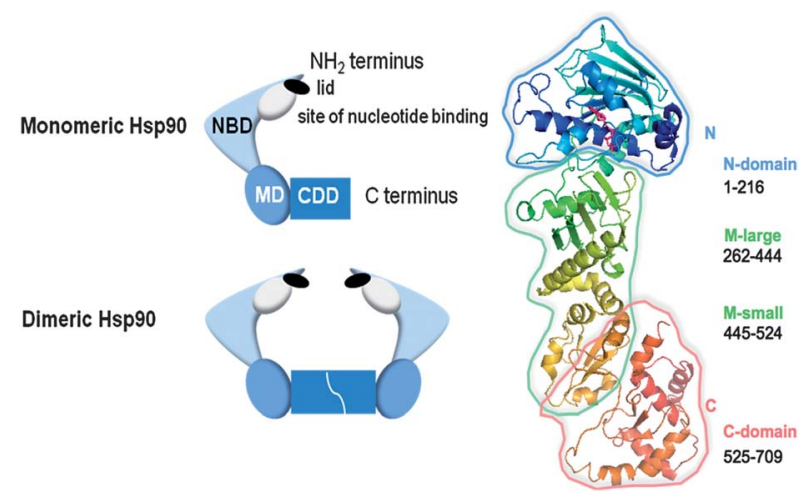

Fig. 3 A graphical presentation of Hsp90 domains and dimeric architecture (left); a crystal structure of the yeast Hp90 monomer in the ATP-bound form obtained from pdb 2CG918 and visualised by pymol software (right). 
By inhibiting the Hsp90 chaperone, interference in cancer cell cycles becomes possible. Thus, compounds that are able to bind to different sites in Hsp90 are potential anticancer drugs. Today three major strategies for inhibiting Hsp90 function are being pursued. These are:

a) the inhibition of ATPase activity by binding at the $\mathrm{N}$-terminal nucleotide binding pocket for which geldanamycin (1), radicicol (13) and PU-H71 (12) are excellent examples (Fig. 7),

b) altering the conformation of Hsp90 activity with small molecules like novobiocin (9) (Fig. 4) that bind to the C-terminal dimerisation domain (CDD) and

c) the inhibition of co-chaperones-binding, such as Cdc37 which is overexpressed in cancer cells, with Hsp90, as imposed by gedunin (10) and celastrol (11) (Fig. 4).

In addition, Hsp90 activity is regulated by targeting sites relevant for the association of Hsp90 with client proteins, sites that modulate Hsp90 activity as well as sites for the inhibition of post-translational modifications, such as phosphorylation, acetylation and $S$-nitrosylation. Details on the biological background of these options are discussed in the following chapters.

\subsection{Functional aspects of Hsp90}

2.2.1 Role in carcinogenesis. Heat shock proteins (Hsp's) are essential for the survival of organisms. In contrast to what the name may suggest, heat shock proteins are not only induced by heat but also by cellular stress situations, such as exposure to UV radiation, nutrient deprivation or oxygen deficiency ${ }^{\mathbf{1 9 , 2 0}}$ Hsp's and especially human heat shock protein 90 (Hsp90) strongly interfere with diverse cellular processes, which include heat shock and other stress responses, signal transduction to chromatin-remodeling, telomerase maintenance and others. ${ }^{11 a}$ Hsp90 is also located in the nucleus where it interacts with chromatin-remodeling complexes. ${ }^{21,22 a}$ A link to the histone methyltransferase SMYD3 was also found. ${ }^{22 \boldsymbol{b}}$ Additionally, Hsp co-chaperones influence DNA helicases in yeast. ${ }^{20 f}$ Examinations in yeast revealed that Hsp82p, the yeast homologue of Hsp90, is required for both DNA binding and extension of the telomerase. ${ }^{23}$ The non-chaperone activity might provide a point of intervention to mitigate excessive telomerase function and may be a noteworthy aspect of cancer etiology. Shortening of telomeres by telomerase activity is correlated with age. For the development of anti-aging concepts, interference in the folding of telomerase by Hsp90 inhibitors may be a feasible strategy. In the context of therapeutic exploitation of Hsp90 inhibition, it is

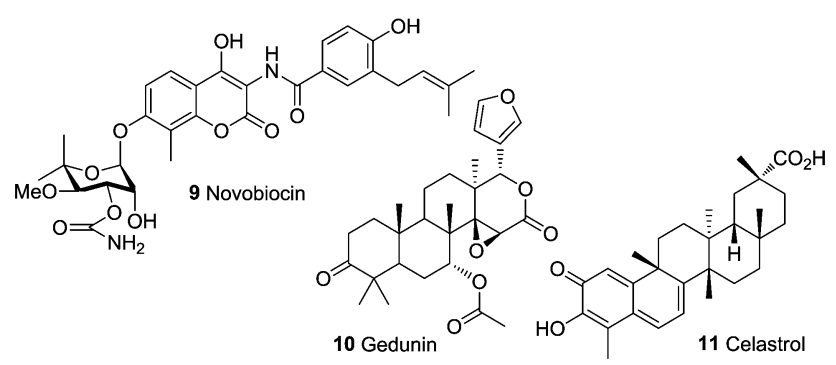

Fig. 4 Structures of novobiocin (9), gedunin (10) and celastrol (11). important to understand the effect and relevance of high or low Hsp90 activity for the cell. Along this line it will be important to establish a correlation between drug-induced levels of Hsp90 and associated toxic side effects.

Besides the role in the nucleosome, Hsp90 client management affects various other cellular processes. Hsp90 governs the folding process of nascent polypeptides leading to maturation and formation of intact and functional three-dimensional structures. ${ }^{24}$ Not only de novo synthesised proteins are folded by Hsp90, but also proteins that have been denatured by cellular stress. The cellular response to stress is highly conserved in prokaryotes and all species of eukaryotes. It represents a general mechanism for the maintenance of cellular processes. In addition, it is a protection mechanism against the formation of protein aggregates in cytosol, whereas in some prokaryotes Hsp90 is dispensable under heat stress. ${ }^{25}$ The initiation of Hsp90 synthesis and other Hsp's are evoked by specific transcription factors, so-called heat shock factors (HSF's). The trimeric form of HSF shows a high affinity for cis-acting DNA sequence elements (heat shock elements; HSEs) in the promoter region of heat shock protein genes. ${ }^{26}$ The bound trimer forms a complex that activates transcription of the Hsp90 gene. Hsp90 is in direct contact with HSF, and stress can significantly increase Hsp90 expression. ${ }^{5,27}$ The unique property of Hsp90 to fold nascent as well as denatured proteins, including mutant forms of proteins, has a special impact for cancer and therefore represents an ideal target for drug development. ${ }^{20 a, 28}$

Due to the antiapoptotic nature of Hsp90, cells can survive stress with the side effect that this property also helps cancer cells in survival. The increased expression of Hsp90 under conditions of stress is a rescue mechanism of cells, because the proteins are protected from degradation by the proteasomic system. Furthermore, the "recycling" of proteins by Hsp90 clearly has advantages in terms of energy balance compared to de novo protein synthesis. For several proteins, which are also known as client proteins or target proteins, Hsp90 is required for preserving their stability and activity. Client proteins comprise up to 600 proteins, including proteins with exceptional features in signal transduction, cell growth and division. For example, receptors such as connexin, ${ }^{29}$ steroid hormones, transcription factors and tumor suppressor proteins are Hsp90 dependent. $^{22 d}$

If protein aggregates are not eliminated by the proteasome, apoptosis is initiated. ${ }^{20 f, 30}$ Thus, this process is a key element in cancer therapy, when Hsp90 function can be suppressed by inhibitors. Besides its importance in cancer therapy, Hsp90 along with its homologues (HtpG's in prokaryotes), has emerged to be an attractive target combating other diseases, since there are homologous representatives in nearly all prokaryotic and eukaryotic cells. ${ }^{31}$ Indeed, a link to other diseases, like neurological disorders, malaria or leishmania, is known. The development of different virus proteins are also Hsp dependent. ${ }^{32}$ Yet another implication of Hsp90 (and Grp94) is in processing antigens and helping to deliver them to the cell surface in MHC complexes or higher Hsp70 levels in human T-cells. $^{33}$ This strategy, however, can lead to a problematic 
situation for adherent therapies, since immune defense could be differently affected by high or low Hsp activity.

Under non stress conditions 1-2\% Hsp90 $\alpha$ and Hsp90 $\beta$ are present in the cell as cytosolic proteins. Hsp90 $\alpha$ serves as the inducible and Hsp90 $\beta$ as the constitutive form. GRP94 is found in the endoplasmic reticulum and TRAP-1 is localised in the mitochondrial matrix. Except for Hsp90N, which has no NTD, all forms of Hsp90, including the bacterial homologue HtpG, are able to hydrolyse ATP. Unlike the other isoforms of Hsp90, the cytosolic function of Hsp90 is highly dependent on a number of co-chaperones, as is described in the next chapter.

2.2.2 The ATP and conformational cycle. The dimeric form of Hsp90 (I/II) acts as a molecular "clip" and suffers from conformational change by an ATP-dependent folding cycle (Fig. 5)..$^{20 a, 32,34}$ During the ATPase cycle, Hsp90 undergoes dimerisation at the N-terminus (II). Association of ATP (III) at this domain is the driving force for this step. The target client proteins are captured with the open form (V-shape) of Hsp90. ${ }^{21,35}$ As a result binding of ATP promotes closure of the lid of the N-terminal ATP-binding pocket, the coming together of the two N-termini of Hsp90 and a conformational change from the closed into the twisted form while "trapping" the client. After hydrolysis of ATP, Hsp90 folds back into its original shape and the open molecular "clip" is regenerated. Binding and subsequent release of the client proteins with the participation of co-chaperones is a dynamic process, whereas the rate of ATP hydrolysis and the conformational change between the different Hsp-conformers varies. For the human Hsp90, this is a slow turnover rate of $3 \mathrm{ATP} \mathrm{h}^{-1} \cdot{ }^{36}$ The conformational change does not necessarily depend on ATP; so the closed form of Hsp90 is also found in the absence of ATP. It is rather assumed that ATP merely shifts the balance between the "open" and "closed" form of Hsp90. Recent data obtained from single molecule measurements showed that ATP can bind at the Nterminus of the open and closed states (III to IV) without strictly forcing the protein into a specific conformation. The switches between the conformational and binding states are mainly thermally driven. Interestingly, ATP binds with different rates to the two monomeric units (negative cooperativity). ${ }^{37}$ These studies also revealed that the C-terminus shows a dynamic behavior. The C-terminus (IV) opens and closes with fast

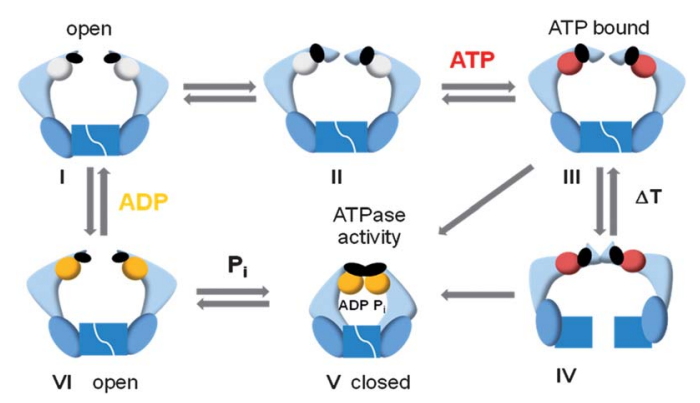

Fig. 5 A model of the ATPase and conformational cycle of Hsp90 proteins; forward and backward reaction rates are different for the individual Hsp90 proteins and may be subjected to regulation by co-chaperones, such as Aha1, Hop, Cdc37 and p23 (see Fig. 6). kinetics, having a modulating effect on the binding of nucleotides to the N-terminal domain. ${ }^{38}$

Although Hsp's and HtpG share a high degree of homology, drastic differences in structure and function between Hsp's and HtpG's are found in crystal structures, the interactome and ATP hydrolysis rates. ${ }^{39}$

The regulation of the ATPase activity and selectivity for client proteins by cytosolic Hsp90 are significantly influenced by cochaperones. In fact, more than 20 co-chaperones regulate Hsp90 by modulating ATP hydrolysis (V/VI) (Aha1, Cdc37, p23), by influencing the conformational flexibility (p23, Sgt1) and by regulating complex assembly (Hop, Cdc37, Sgt1). They may also be required for folding other co-chaperones, such as Hsp70 and Hsp40. ${ }^{40}$ During the ATPase cycle in eukaryotes different cochaperones assemble to yield the so-called "multi-chaperone" machinery. ${ }^{41}$ The whole process was examined in detail for the maturation of a steroid hormone receptor in yeast. The cycle starts with association of the newly synthesised and still unfolded protein to an early complex of heat shock proteins Hsp70/Hsp40 (I) (Fig. 6). ${ }^{19 b}$ Complexation of this intermediate complex (I) to Hsp90 is facilitated by another co-chaperone called Hop, which contains the tetratricopeptide repeat (TPR) receptor domain and forms complex $\left(\mathbf{I I} / \mathbf{I I}^{\prime}\right)$. TPR, which has PPIase activity, binds to the MEEVD motif (several Hsp's and cochaperons have this element, which is located at the CTD) in Hsp90. This step prevents dimerisation of the N-termini of Hsp90 and serves as an adapter for transfer of the client protein from Hsp70 to Hsp90 (III). This Hsp90/Hsp70/Hop complex acts as the central intermediate in the Hsp90 cycle. ${ }^{42}$ After binding ATP (IV) the intermediate complex forms a non-symmetric complex. In the presence of p23 this late complex (V) is stabilised, by which the co-chaperones Hop, Hsp 40 and Hsp70 are released. Both, p23 and Cdc37 inhibit HSP90 ATPase activity and bind near the ATP-binding pocket of Hsp90. Cdc37 fixes the $\mathrm{N}$-domain in an open state form, thereby preventing dimerisation. After hydrolysis of ATP the open conformation of Hsp90 (VI) is liberated. Another co-chaperone, called Aha1 (activator of Hsp90 ATPase, non TPR co-chaperone), can alternatively bind to the Hsp90 dimer $\left(\mathbf{I I}^{\prime}\right)$. This chaperone thereby forms a link between the middle domain $\mathrm{M}$ or the client binding site, and

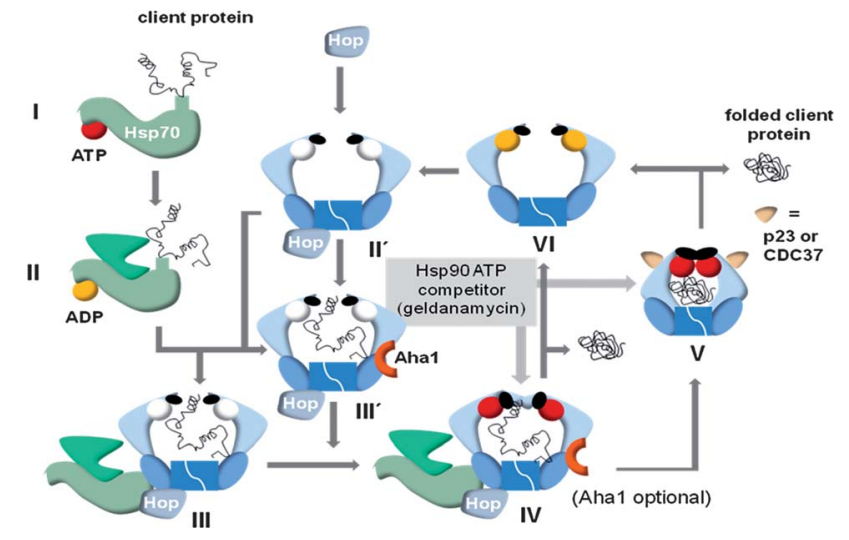

Fig. 6 The folding cycle of Hsp90 with co-chaperones. 


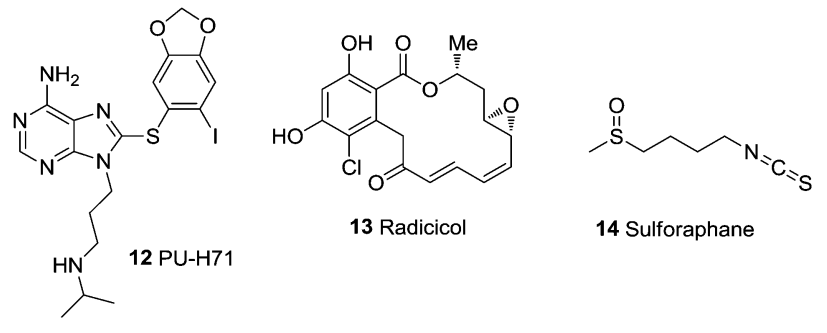

Fig. 7 The structures of PU-H71 (12), radicicol (13) and sulforaphane (14).

the N-domain, the ATP binding site (complex III'). This relaxed open state undergoes a conformational change from a closed and ATP free state to a closed ATP-bound state (IV).$^{43}$ Aha1 is so far the only known activator of ATPase activity by asymmetric binding to a single Hsp90 middle domain in the open configuration. Its binding induces the switch of the N-domains into the closed state, leading to the acceleration of the ATPase cycle. ${ }^{43}$ It has been proposed, that Aha1 competes for p23. Accompanied by ATP hydrolysis, the correctly folded protein is released from the multi-chaperone complex, furnishing complex (VI) directly. Several other co-chaperone proteins like Cdc37 act as adapters by recruiting a specific range of client proteins (kinases). They bind to the open form of Hsp90, so that the dimerisation of the $\mathrm{N}$-terminal domain is prevented and the ATPase cycle is interrupted.

Having outlined the basic features of the ATPase cycle, the focus will next be directed both towards regulation as well as integration of client interaction. At the beginning of the cycle, the N-terminal dimerisation can be thwarted by Hop (Sti1) or Cdc37. ${ }^{44}$ Hop has two TPR domains that bind a conserved domain at the C-terminus of Hsp90 (sequence MEEVD) and Hsp70, respectively. ${ }^{39,45}$ It should be noted, that both Hsp70 and Hsp40 induce binding of steroid hormone receptors to Hsp90 during the process of receptor activation. ${ }^{45}$ Meanwhile, Cdc37 constitutes a co-chaperone that plays a key role as an adapter for the kinase fold, selectively enabling strong or weak client interactions. ${ }^{\mathbf{1 4 , 4 6}}$ These observations unravel the heterogeneity of the co-chaperones for different client classes and provokes the need to identify 'general' co-chaperones, i.e. those that participate at least in the majority of folding processes. This approach should provide domain-specific Hsp90 inhibitors that do not bind to the NTD or CTD. It is known that p23 and Sgt1 stabilise the closed ATP-bound state and slow down ATP hydrolysis. ${ }^{44 a}$ Therefore, these and other co-chaperones play a fundamental role beyond regulating the cycle. For instance, in selected cases these co-chaperones have been linked to quality control of the client proteins, as shown for the mutant cystic fibrosis transmembrane conductance regulator (CFTR). ${ }^{48}$ Still, significant knowledge gaps have to be acknowledged. There are likely many more co-chaperones than those described here. A first step towards a rational drug design would be to understand how many co-chaperones involved in a given folding cycle need to be addressed by a drug to achieve best inhibition. It has to be determined, if initial bonding contacts are mediated by cochaperones or by the client itself. If possible, targeting co- chaperone interaction seems to be more sensible, given the much greater variety of existing clients compared to co-chaperones. For solitary clients a surface motif that mediates binding to an Hsp90-Cdc37 complex has been analysed for kinase clients. ${ }^{47}$ Here, the $\alpha \mathrm{C}-\beta 4$ loop region of various members of the kinase families is sufficiently conserved and represents a common recognition motif. Apart from that, there is little information available so far on other client classes or specific client-binding sites at Hsp90.

2.2.3 Post-translational regulation of Hsp90. Post-translational modifications, that include phosphorylation, acetylation, nitrosylation and methylation, are supposed to be fine tuning mechanisms of the cell for adjusting Hsp90 activity. ${ }^{49}$ When the charged linker region of Hsp90 is phosphorylated, client maturation of the aryl hydrocarbon receptor (AHR) is hindered..$^{50}$ This receptor is a cytosolic transcription factor. It is attached to several co-chaperones binding several exogenous ligands, such as natural plant flavonoids, polyphenolics and indoles, as well as synthetic polycyclic aromatic hydrocarbons and dioxin-derived compounds. In addition, many kinases that regulate Hsp90 phosphorylation are Hsp90 clients themselves. ${ }^{51}$ Acetylation can influence client protein maturation and co-chaperone binding, and it is reported that acylation may reduce ATP binding of $\mathrm{Hsp}_{0 .}{ }^{52} S$-nitrosylation at the C-terminal domain of Hsp90 leads to the reduction of Hsp90 ATPase activity. ${ }^{53}$ SMYD3, a lysine methyltransferase, is upregulated in several cancer cells, and it was found that its catalytic activity is enhanced by the interaction with Hsp90. ${ }^{54}$

2.2.4 Client processing. One prevalent property of Hsp90 is its contribution to client protein folding, maturation and activation. Although it is generally accepted that Hsp90 mainly interacts with proteins that are already folded to a large degree, the extent of folding of different client classes is not well defined. ${ }^{19 b}$ The presence of tertiary or quarternary structural elements in the client, even if it is non-native, favours the search for common binding motifs, but this process requires co-chaperones or cofactors. In the case of repeated unsuccessful folding or aggregation, the E3 ubiquitin ligase CHIP, that is recruited to Hsp90, can initiate degradation via the proteasome pathway. The whole scenario has become more complex by a recent finding that Hsp90 interacts with the p53 client, in that p53 is actually unfolded by Hsp90 $\alpha$, as judged by NMR spectroscopic measurements. ${ }^{55}$ As a consequence p53 adopts a molten globule-like state. Thus, Hsp90 should not be solely regarded as a chaperone that simply helps transform its clients into a stable and fixed tertiary structure. Instead, Hsp90 also stabilises the dynamic molten globule state, which may foster other protein interactions for those clients.

\section{Biomedical aspects of Hsp90}

\subsection{Selection criteria for Hsp90 as a target in chemotherapy}

Hsp90 plays a key role in a diverse range of diseases, such as ischemia, reperfusion, infections and neurodegenerative diseases. ${ }^{56}$ However, from a pharmaceutical point of view its participation in the development and control of various cancers is most important. In cancer cells, an increased Hsp90 
expression parallels the overexpression of oncoproteins like Erb2, EGFR, c-RAF, HIF-1 and telomerase. These facts make Hsp90 a key target in cancer chemotherapy. ${ }^{57}$ Signal transduction pathways like G-protein-coupled receptors, low-molecular-weight GTP binding protein, tyrosine kinase, Ser/Thr kinase, ion channel receptors, nuclear pore channel and nuclear transcription factors are important elements in several diseases and may also expand the opportunities for Hsp90based therapies. By identifying cancer-specific interactomes, such as the Hsp90 inhibitor PU-H71 (12), Hsp90-dependent oncogenic client proteins have been captured by pull down assays. ${ }^{58}$ This assay helped to comb through the cancer-linked proteome using mass spectrometry and new aberrant signalosomes in CML cells (Chronic Myelogenous Leukemia; cancer cell lines of white blood cells) were found. One important key regulator that was identified by this method is STAT5. STAT5 is a molecular regulator for proliferation, differentiation and apoptosis in hematopoietic cells, which are multipotent stem cells giving rise to all new types of blood cells.

Among the relevant oncoproteins, the transcription factor p53 is probably the most prominent one, sometimes being referred to as "guardian of the genome". In about $50 \%$ of all cancers, p53 is damaged and the loss of function is caused by so-called "hot spot" mutations in the DNA-binding region. ${ }^{59}$ Functionally, the detection of DNA damage and subsequent initiation of apoptosis or repair mechanisms are the most important features of p53. A rescue mechanism of a defective p53 system is fatal, because the mechanisms of apoptosis can thus be evaded. Physiologically, tumor cells are under constant stress; so proteins actually tend to denature. ${ }^{60}$ This situation leads to an increased consumption of molecular chaperones, as reflected in an increase of the cytosolic Hsp90 fraction to up to $4-5 \%$, which leads to higher heat shock protein activity in tumor cells compared to healthy cells. ${ }^{61,62}$ The effect of Hsp90 blockers is more pronounced in tumor cells than in healthy cells due to the higher concentration of Hsp90, which is accompanied by overproduction of Hsp90-dependent oncoproteins. The increased presence of the "multi-chaperone" machinery in cancer cells results in a higher affinity for inhibitors that bind to the N-terminus of Hsp90. In normal cells, the major amount of Hsp90 is not present in multi-chaperone complexes and in this state it shows lower affinity for inhibitors. As a result, inhibition initiates apoptosis or stops elevated growth rates.

In essence, the pronounced accumulation of Hsp90 in cancer cells along with the opportunity to develop selective inhibitors against Hsp90 and cancer relevant multi-chaperone complexes are important selection criteria to identify Hsp90 as a promising target in anticancer therapy.

\subsection{Functional domains of Hsp90 - the Achilles heel}

The establishment of Hsp90 as a biological target in anti-tumor therapy initiated the search for inhibitors in academia and the pharmaceutical industry. The most prominent Hsp90 inhibitor is geldanamycin (1), that was first isolated from the actinomycete Streptomyces hygroscopicus. Geldanamycin acts by binding
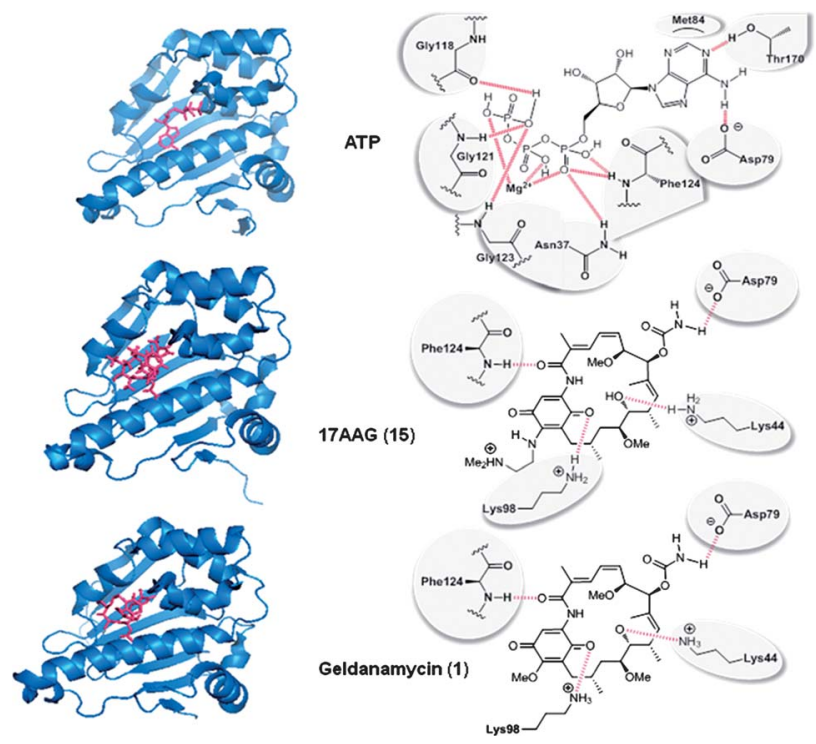

Fig. 8 Graphics of X-ray structures of Hsp90/small molecules (ATP, geldanamycin (1) and 17AAG 15) (left) and important molecular interactions (right): a) Hsp90N with ATP $(3 T 0 Z)^{65}\left(E_{50}=200 \mathrm{nM}\right)$; b) Hsp90N with geldanamycin $\left.(1 \mathrm{YET})^{66}\left(\mathrm{IC}_{50}=20-200 \mathrm{nM}\right) ; \mathrm{c}\right) \mathrm{Hsp90N}$ with 17AAG $(1 \mathrm{OSF})^{67}\left(\mathrm{IC} \mathrm{C}_{50}=24 \mathrm{nM}\right)$. All structural data are deposited at www.pdb.org.

to the N-terminal ATP-binding site of Hsp90, the ATPase function (see Fig. 6). ${ }^{63}$ The affinity of geldanamycin for the ATPbinding site is 100-fold higher than that of ATP (Fig. 8).

It binds to the site in that it adopts the structure of an unfolded polypeptide chain. The most important contacts of ATP interaction sites on the Hsp90N crystal are Met84, Asp79, Gly118, 121, 123, Phe124 and Thr170, while Asp79, Lys44, Lys98 and Phe124 are relevant for geldanamycin binding and the semisynthetic derivative 17AAG 12 (vide supra). They are not only relevant for the inhibitory role of geldanamycin but also for the semisynthetic derivative 17AAG 15 (vide supra). Upon binding of geldanamycin and analogues, Hsp90 is retained in its ADP-bound conformation so that these ligands prevent Hsp90 from promoting the ATP cycle (Fig. 5 and 6). As a result, the client protein is ubiquitinated and then degraded by the proteasomic machinery. Moreover, the inactivation and destabilisation of the hypoxia-induced factor (HIF)- $1 \alpha$ is induced. This results in the degradation of HIF- $1 \alpha$. As a consequence of inhibition, apoptosis or programmed cell death is initiated. Another competitive ATPase binder is the polyketide radicicol (13). It was isolated as a secondary metabolite from the fungi Monocillium nordinii and Monosporium bonorden. Only recently, sulforaphane (14), an isothiocyanate derived from cruciferous vegetables, has been shown to possess potent chemopreventive activity by inhibiting pancreatic cancer cell growth $\left(\mathrm{IC}_{50} \sim 10-\right.$ $15 \mu \mathrm{M})$. It has been suggested that it also disrupts proteinprotein interactions in Hsp90 complexes. ${ }^{64}$

\section{Hsp90 and drug design ${ }^{68}$}

The interest in Hsp90 inhibitors has recently found an additional impetus, because heat shock proteins can also serve as a 
target in the treatment of pathogenic diseases, such as malaria and leishmania, as well as against neurological disorders. ${ }^{69}$ Although geldanamycin is a feasible drug candidate for targeting Hsp90, the search for improved drug candidates is still intensely pursued, particularly in order to reduce toxic side effects. Geldanamycin exerts a high degree of hepatotoxicity, which is thought to result from detoxification processes e.g. when a quinonimine is formed or thiols (such as glutathione) add to the quinone moiety by means of a Michael reaction. ${ }^{70}$ Besides pharmacokinetic aspects, resistance, including polymorphism of the N-terminal binding site may render potential drugs like geldanamycin ineffective.

Mutational analysis of Hsp90 disclosed that the middle domain, particularly Trp300 and Glu341, have a predominant role in recognising client proteins in the closed dimeric structure. ${ }^{71}$ Trp300 is part of an amphipathic loop structure that exerts hydrophobicity towards the core and hydrophilicity towards the solvent. This bifunctional arrangement may work like a 'hook' that captures the client via hydrophilic interactions. Since some clients may present a hydrophobic patch for interaction, the inner hydrophobic site in Hsp90 could mediate the process by insertion of the patch into this hydrophobic space. ${ }^{72}$ These preliminary studies demonstrate that it would be highly desirable to identify a 'minimum client binding site', shared by the bulk of each client class. In fact, this would reduce the possible multiple interaction sites to one common point of contact, amenable to inhibitor development. Based on the X-ray analysis of the ATP binding pocket, other drug classes, including purine scaffold derivatives and tetrahydrobenzopyrimidines, have been evaluated..$^{73}$

A recurring problem common to all inhibitors that target the $\mathrm{N}$-terminal ATPase site is the subsequent induction of Hsp70 and Hsp27 via Hsf1 (not shown). The proliferative effect of Hsp70/27 clearly counteracts the desired apoptotic effect to some extent. The degree of this effect, however, depends on the specific tumor. One strategy to circumvent this problem is to focus on other binding sites for inhibitors. Indeed, the Cterminus is a feasible alternative although the underlying mechanism is much less clear. The inhibition of Hsp90 imposed by eliminating the TPR2-mediated Hop/Hsp90 interaction has been demonstrated. ${ }^{74}$ Novobiocin $(9)^{75,76}$ and cisplatin are both known to bind to this Hsp domain. Since a second ATP-binding site close to the C-terminus is hypothesised, it cannot be excluded that inhibition may be linked to this site instead. ${ }^{77}$ However, binding to this site is often weak and a more precise understanding of this area of Hsp90 will be mandatory for utilising it as a site for drug development. Notably, the direct inhibition of the client binding site is unknown and has not been studied in great detail so far.

\section{Synthetic approaches towards natural product based libraries of Hsp90 inhibitors}

\subsection{General considerations}

In view of its central position in a myriad of cell processes and its special role in the life cycle of cancer cells there is a quest for the development of highly potent inhibitors targeting Hsp90.

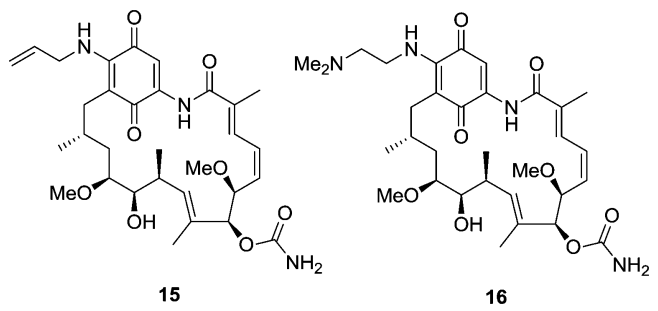

Fig. 9 The structures of tanespimycin (17-AAG) 15 and alvespimycin (17DMAG) 16.

Geldanamycin (1) has emerged as a showcase from natural sources in this arena. However, the hepatotoxic side effects, the low solubility in aqueous solutions associated with limited bioavailability and its overall reduced chemical stability have hampered the clinical use of geldanamycin. Instead, several new analogues, such as tanespimycin (17-AAG) 15 and alvespimycin (17-DMAG) 16 are drug candidates that have reached clinical trials at different stages (Fig. 9). The following discussion will provide a detailed description on strategies of how to generate derivatives of this lead compound that are structurally as complex as geldanamycin. This showcase demonstrates the synthetic difficulties and restrictions associated with creating related natural product libraries.

Total- and semisyntheses are most widespread approaches in natural product chemistry. ${ }^{78} \mathrm{~A}$ third synthetic tactic relies on implementing biological tools into synthetic strategies. These may be enzyme cocktails from secondary metabolisms or organisms engineered in the biosynthesis of the target natural product. Powerful methods are combinatorial biosynthesis ${ }^{79}$ or mutasynthesis. ${ }^{\mathbf{8 0}-\mathbf{8 2}}$ These are combinations of partial biosynthesis and semisynthesis ${ }^{83}$ or precursor directed methods. ${ }^{84}$ Besides their biological potency, ansamycin antibiotics, such as

By total synthesis

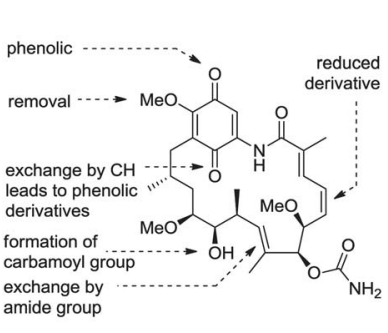

By combination of "biosynthesis" and semisynthesis

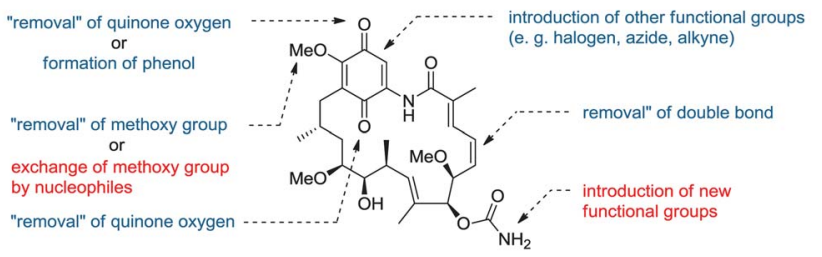

Fig. 10 An overview of sites of modifications achieved by total synthesis, by semisynthesis and by combined chemical synthesis and biosynthesis. 
geldanamycin, are also unique from a synthetic point of view, because all three synthetic tactics have been successfully pursued, as summarised in Fig. 10. Details on how modifications were achieved are given in the following chapters.

\subsection{Total synthesis approaches to geldanamycin and derivatives}

The total synthesis of geldanamycin (1) and related ansamycin natural products is still a formidable multi-step challenge. Herbimycin A (2) was the first natural product of this class of ansamycin antibiotics to be synthesised by Nakata et al. in $1991 .^{85} \mathrm{~A}$ decade later, Andrus and co-workers achieved the first total synthesis of geldanamycin (1). This work has become a benchmark synthesis, because it unravelled some very challenging hurdles. Thus, the best timing for incorporating the aromatic/quinone moiety into the backbone has to be considered and along with this it is crucial to choose the best protecting group strategy for the functional groups on the aromatic ring. Thus, the methoxy group at C-17 is prone to undergo side reactions when selective demethylation at C-18 and C-21 of advanced synthetic intermediate $\mathbf{1 7}$ was pursued (Scheme 1). Instead of formation of the quinone form of geldanamycin formation, the oxidative deprotection preferentially yielded ortho-quinone derivative 18 (Scheme 1). The low yielding synthesis of geldanamycin (1) could later be improved by Andrus and co-workers by switching to MOM protection of the hydroquinone moiety. ${ }^{86}$

Panek and co-workers disclosed an alternative total synthesis, which provided geldanamycin (1) in 20 linear steps in $2 \%$ overall yield (Scheme 2$) \cdot{ }^{87} \mathrm{~A}$ key to success was the choice of isopropylethers as protection for the hydroquinone moiety. Attachment of the ketide chain to the aromatic ring $\mathbf{1 9}$ was achieved by a [4+2] ring closure with allyl silane $\mathbf{A}$ to yield two diastereomers 20a and $\mathbf{2 0 b}^{\mathbf{8 8}}$ followed by a stereoselective hydroboration that furnished compound 21. This remarkable pyran formation is suggested to proceed via a cyclic transition state, which is formed after removal of the $\alpha$-siloxy group in $\mathbf{A}$. Subsequent reductive ring opening of the pyran ring using $\mathrm{Sc}(\mathrm{OTf})_{3} / \mathrm{Et}_{3} \mathrm{SiH}$ yielded key fragment 22 .

The macrolactamisation to $\mathbf{2 4}$ was accomplished by an intramolecular copper-mediated Hartwig-Buchwald type reaction between the aryl bromide moiety and the amide functionality in 23. The benzyl ether and both isopropyl groups were removed by using $\mathrm{AlCl}_{3}$ in the presence of anisole to furnish
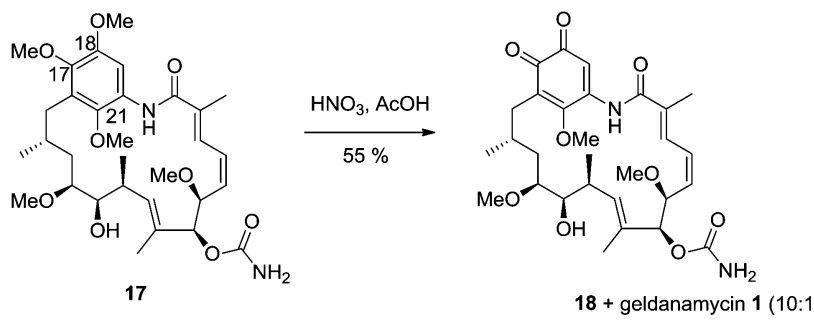

Scheme 1 Ortho-quinone 18 formation by oxidative demethylation of geldanamycin derivative 17.

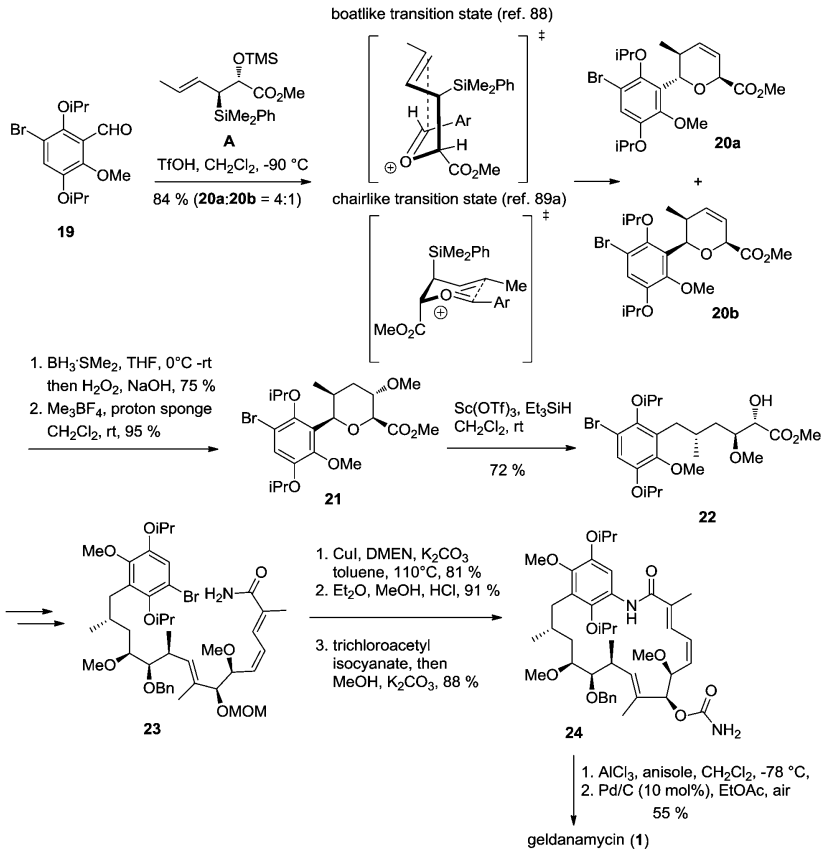

Scheme 2 Geldanamycin synthesis according to Panek et al.; ${ }^{87}\left(\mathrm{DMEN}=\mathrm{N}_{\mathrm{N}} \mathrm{N}^{\prime}\right.$ dimethylethylenediamine).

dihydrogeldanamycin that was subsequently treated with Pd/C under oxidative conditions to give geldanamycin (1) in 55\% yield over two steps.

Furthermore, Panek's group utilised this synthetic approach for the preparation of autolytimycin (4), reblastatin (5), and three analogues 28-30. Predictably, the end game for these phenolic ansamycin derivatives turned out to be easier to

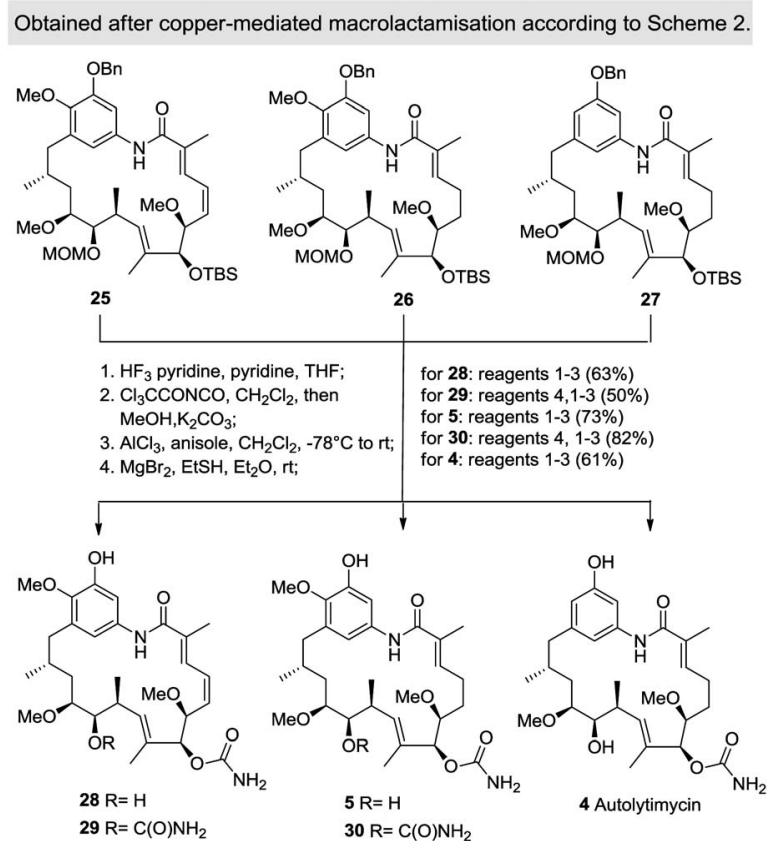

Scheme 3 Preparation of autolytimycin (4), reblastatin (5) and derivatives 28-30. 

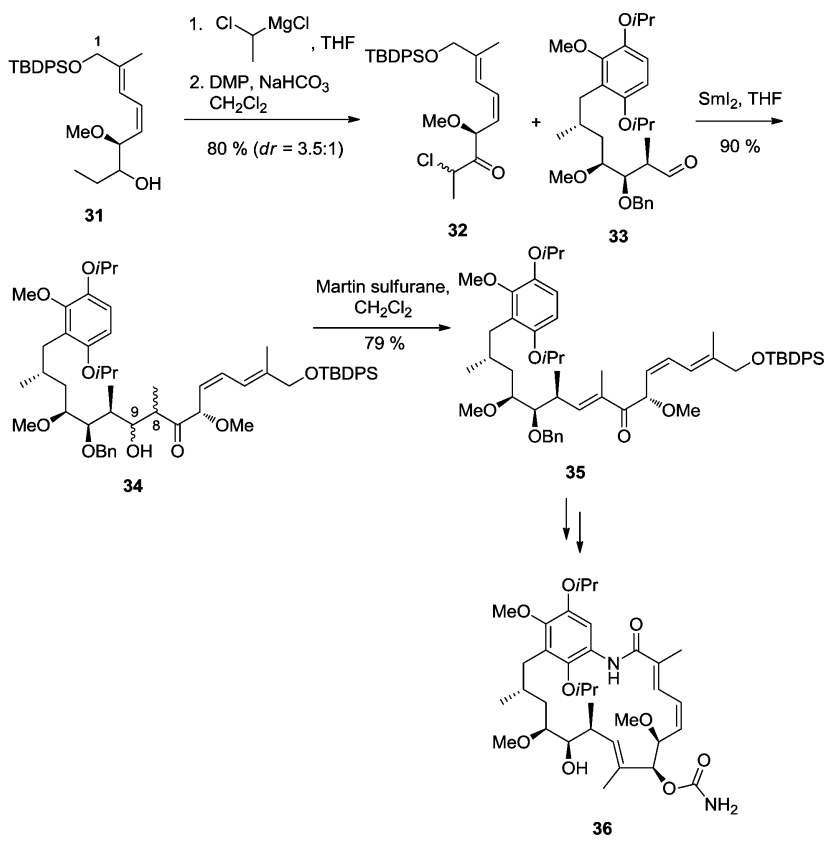

Scheme 4 Total synthesis of 18,21-diisopropyl-geldanamycin hydroquinone $\mathbf{3 6}$ (according to Bach et al. ${ }^{90}$ ).

perform than for the hydroquinonoic geldanamycin described above (Scheme 3). ${ }^{89}$

Bach's work ${ }^{90}$ (Scheme 4) demonstrates that future work on the end game synthesis of quinone-based macrolactam antibiotics will have to address an alternative protection strategy for the hydroquinone moiety. Bach et al. based their sequence on connecting $\mathrm{C} 8$ and $\mathrm{C} 9$ via a $\mathrm{SmI}_{2}$-mediated Reformatsky coupling reaction of $\alpha$-chloro ketone 32 with aldehyde 33 to yield advanced intermediate 34 . This product was transformed by Martin elimination into enone $35 .{ }^{90}$ However, after lactam formation all efforts failed so far to remove the isopropyl groups so that the total synthesis had to be terminated at the stage of the bisisopropyl geldanamycin derivative 36 (Scheme 4). Clearly, geldanamycin (1) remains a true synthetic challenge and future SAR studies cannot be expected to rely on total syntheses approaches alone.

Andrus et al. simplified the total synthesis approach to new geldanamycin derivatives by installing an amide bond into the ansa chain. By merging two different fragments 37 and 38 with the advanced ansa chain fragment $\mathbf{3 9}$ they finally accessed

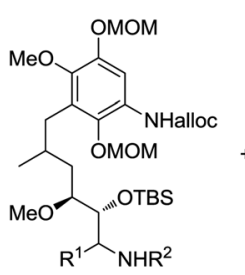

$37 \mathrm{R}^{1}, \mathrm{R}^{2}=\mathrm{H}$ $38 \mathrm{R}^{1}=(R)-\mathrm{Me}, \mathrm{R}^{2}=\mathrm{Me}$

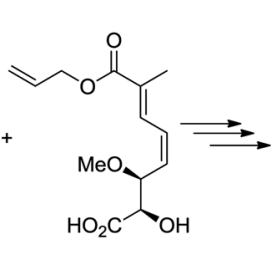

39

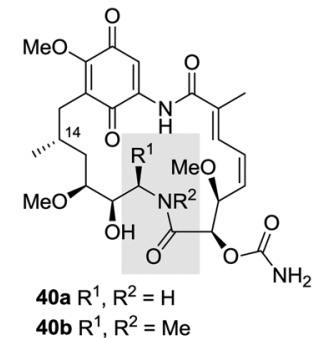

Scheme 5 A simplified total synthesis of geldanamycin derivatives $\mathbf{4 0 a}$ and $\mathbf{4 0 b}$. geldanamycin 8,9-amido-geldanamycin derivatives 40a and 40b, respectively (Scheme 5). Unfortunately, both new geldanamycin derivatives have lost their ability to promote HER2 degradation in SK-Br3 cells $\left(\mathrm{ED}_{50}>20 \mu \mathrm{M}\right.$, compared to geldanamycin with an $\mathrm{ED}_{50}$ of $\left.5 \mathrm{nM}\right) .^{91}$

\subsection{Semisynthetic approaches}

5.3.1 Semisynthetic alterations at the quinone/hydroquinone moiety. Semisynthesis is a widely employed technique to access new derivatives of complex natural products. The major challenge from a chemical point of view is to find highly chemoselective transformations for a given multifunctional and often chemically labile natural product.

Most known geldanamycin derivatives were prepared by semisynthesis and in the majority of cases they are modified at C-17. Rinehart et al. synthesised geldanamycin derivatives, named geldanazines and geldanoxazinones by reacting geldanamycin with $o$-phenylenediamines and $o$-aminophenols, respectively, via imine-formation at C-18 and substitution of the C-17-methoxy-group by means of an addition/elimination process (Scheme 6). Both groups of derivatives showed low inhibitory effects on the bacterial RNA polymerase but they exerted higher potency in inhibiting the DNA polymerase of tumor cells compared to geldanamycin (1), while showing reduced cytotoxicity. Remarkably, all new geldanamycin derivatives except 44a, 43e and peptide $\mathbf{4 3 g}$ inhibited a new biological target, namely the RNA-dependent DNA polymerases (RDDP) of the Rauscher Leukemia Virus (RLV), which geldanamycin does not address. ${ }^{92}$

Other "early" semisynthetic modifications of geldanamycin included hydrazone and oxime-formation at C-19 as depicted in 46 (Scheme 7). These were obtained by Mannich condensation of geldanamycin (1), followed by the reaction of the proposed intermediate alkylimines 45a with amines or hydroxylamines, respectively. These derivatives showed good activity against tumor viruses while exhibiting lower

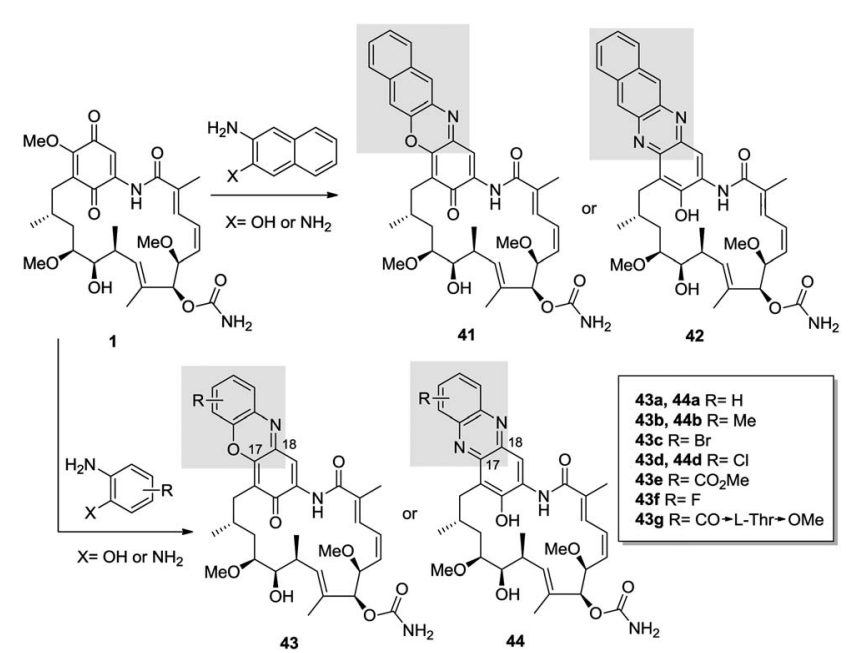

Scheme 6 Semisynthesis towards geldanoxazinones 41, 43a-e,g and geldanazines $\mathbf{4 2}$ and $\mathbf{4 4 a , b , d , f . ~}$ 


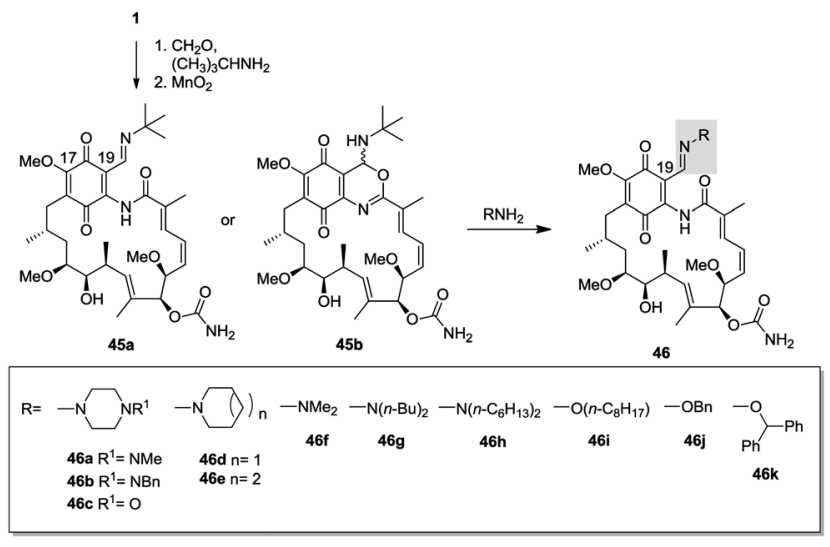

Scheme 7 Semisynthesis towards geldanahydrazones $\mathbf{4 6 a - k}$.

cytotoxicity compared to geldanamycin (1) (Scheme 7). The hydrazones 46b and 46c showed 3000-25 000 times lower antiproliferative activity towards BALB 3 T3 cells than geldanamycin, while the oxime $\mathbf{4 6 j}$ was only 200-500 times less cytotoxic. ${ }^{93}$ When repeating this experimental work, Schnur and cowokers ${ }^{94}$ also prepared compound 46a and beyond this they assigned the originally proposed intermediate $45 \mathrm{a}$ to be the cyclic isomer $\mathbf{4 5 b}$.

In 1995 Schnur et al. reported several semisynthetically generated geldanamycin derivatives that were modified at C-17 and at C-19, respectively. ${ }^{95}$ Geldanamycin (1) and 4,5-dihydrogeldanamycin $\mathbf{4 7}$ were reacted with alkylamines to yield 17-demethoxy-alkylamino-derivatives 48 and 49 (Scheme 8). In
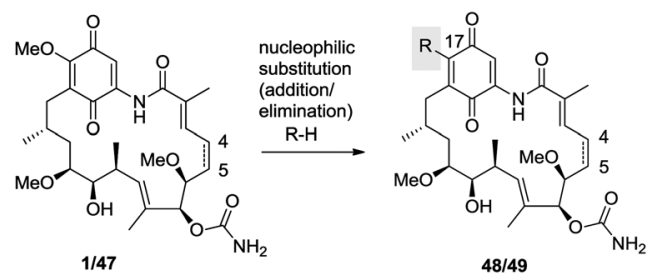

1/48: geldanamycin

47/49: 4,5-dihydrogeldanamycin

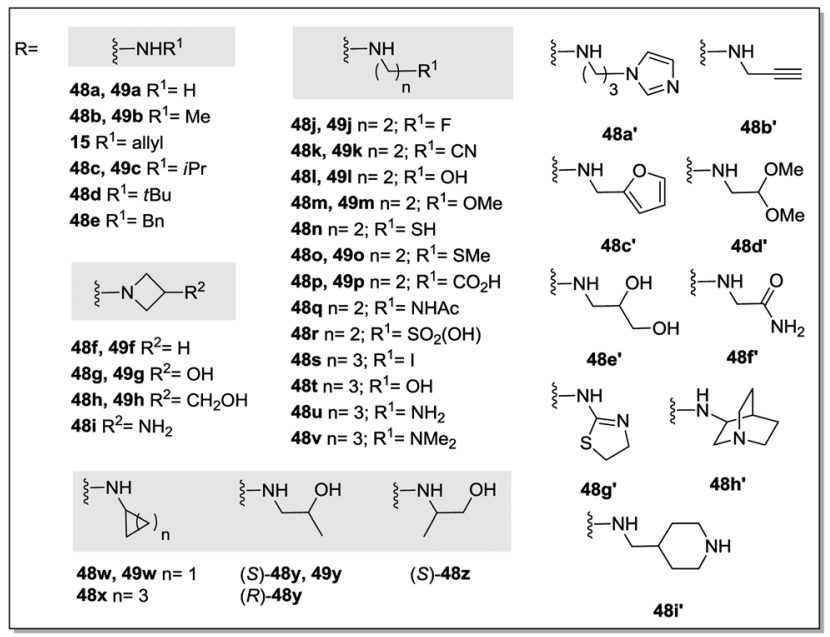

Scheme 8 Semisynthesis of C-17 quinone derivatives $\mathbf{4 8}$ and (4,5-dihydro) 49. case of sterically hindered amines, the $\mathrm{C}-17$ position was the preferential site of attack; instead the C-19 alkylamino- or the C-17, C-19 bisalkylamino compounds were obtained. This modification allowed to rapidly generate a structurally diverse library of simple geldanamycin analogues from which two the derivatives $17-N$-allylamino-17-demethoxygeldanamycin (17AAG; tanespimycin) 15 and 17-dimethylaminoethylamino-17-demethoxygeldanamycin (17-DMAG; alvespimycin) 16 (Scheme 12) were further elaborated as drug candidates. ${ }^{96}$

These first semisynthetic studies revealed improved biological potency/activity when small, sterically unconstrained aminogroups are introduced at C-17 (e.g. 48a, 15, 48c, 48g-h, 48k-l, 48n, 48x and $48 c^{\prime}$ ) with respect to geldanamycin (1). In fact, geldanamycin $\left(\mathrm{IC}_{50} \sim 70 \mathrm{nM}\right)$ shows moderate in vitro potency of $e r b B-2$ inhibition in SKBR-3 cells. It is approximately 4 -fold more potent than herbimycin $\mathrm{A}(2)\left(\mathrm{IC}_{50}=300 \mathrm{nM}\right)$ and three times more active than 4,5-dihydrogeldanamycin $\left(\mathrm{IC}_{50}=\right.$ $230 \mathrm{nM}$ ) 47. Derivatives bearing the (fluoroethyl)amino $\mathbf{4 8 j}$ $\left(\mathrm{IC}_{50}=12 \mathrm{nM}\right)$, the (cyanoethyl)amino $48 \mathrm{k}\left(\mathrm{IC}_{50}=17 \mathrm{nM}\right)$, and the azetidinyl $48 \mathrm{f}\left(\mathrm{IC}_{50}=23 \mathrm{nM}\right)$ substituent are apparently the most potent derivatives in this geldanamycin series. Likewise also potent 4,5-dihydrogeldanamycin derivatives (49a-c, 49f,g, 49i-m, 49o, 49y and (S)-49y) bearing the same kind of substituents are of importance. Here, the methylamino 49b $\left(\mathrm{IC}_{50}=12 \mathrm{nM}\right)$, and the azetidinyl $49 \mathrm{f}\left(\mathrm{IC}_{50}=14 \mathrm{nM}\right)$ substituents showed biological activity against $\operatorname{erbB}-2$ at low concentrations. Geldanamycin derivatives $48 f, 49 f, 48 j, 48 k$ and $49 b$ showed highest activities. Small amino-substituents at C-17 carrying acidic functions are less potent (see 48p, 48r). In contrast, basic groups and hydroxyl groups are tolerated. When substituents become bulkier or arylalkylamines are introduced the activity is reduced.

Later, Le Brazidec added amides, carbamates and ureas as well as 17-aryl derivatives to the portfolio of $17-\mathrm{N}$-geldanamycinderivatives by making 17-amino-17-demethoxygeldanamycin (17-AG) 48a accessible. This derivative was generated by treatment of geldanamycin with methanolic ammonia and was further transformed into amides, ureas and carbamates (Schemes 9-11). ${ }^{97}$

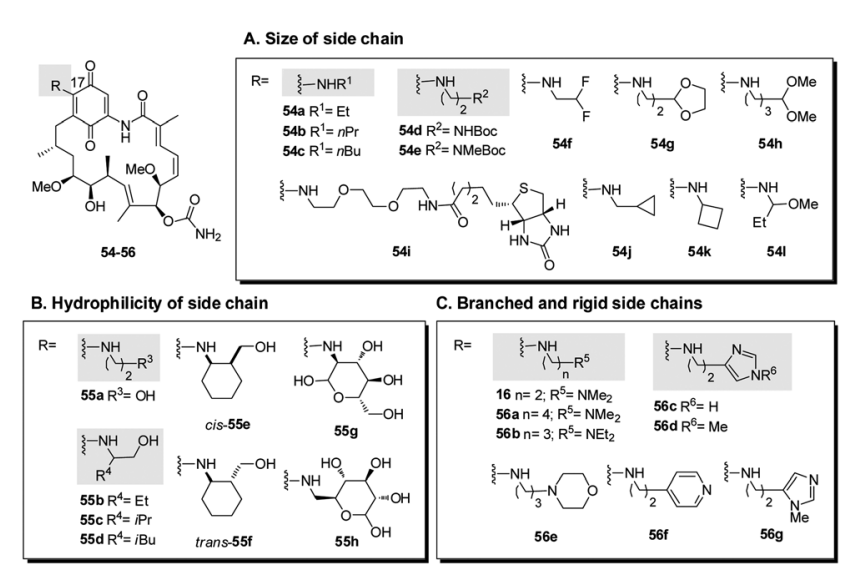

Fig. 11 Semisynthesis of geldanamycin derivatives $\mathbf{1 6}$ and 54-56 modified at C-17. 


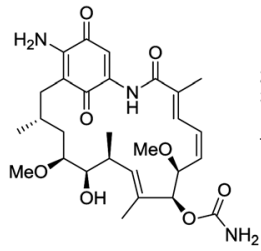

48 a

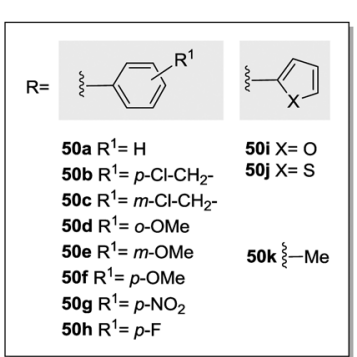

Scheme 9 Semisynthesis of C-17-derivatives $\mathbf{5 0 a - k}$
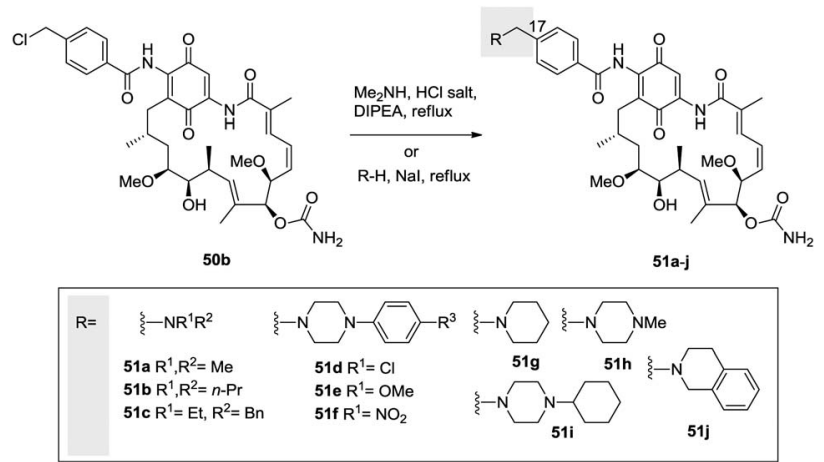

Scheme 10 Semisynthesis of C-17 modified derivatives $\mathbf{5 1 a - j}$

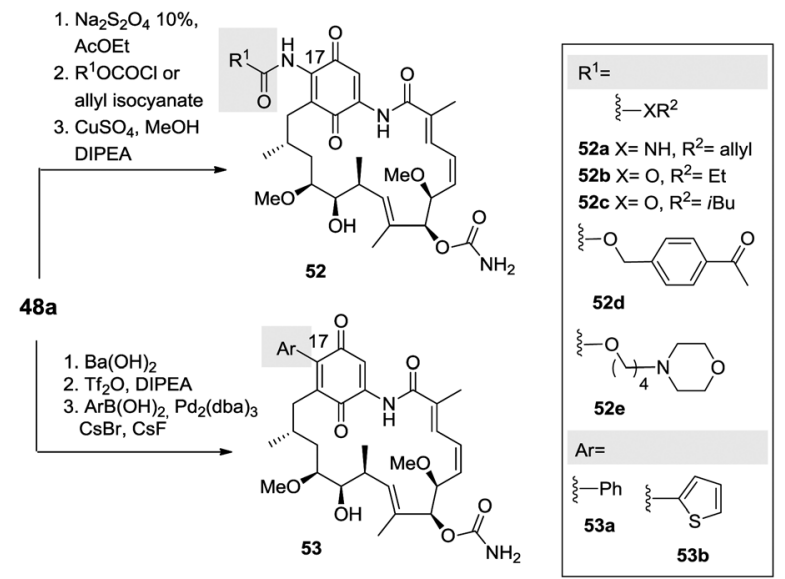

Scheme 11 Semisynthesis of C-17-modified geldanamycin derivatives 52a-e and $\mathbf{5 3 a , b}$.

The aromatic amides $\mathbf{5 0 a}-\mathbf{c}$ and $\mathbf{5 0 g}-\mathbf{h}$ are more potent than the aliphatic analogues 50k. Structural changes with respect to size and polarity resulted in reduced activity (50i, 50j). Increasing the electron density in the aromatic system turned out to be particularly effective for ortho and meta substituents. 50d and 50e (both $\mathrm{IC}_{50}=180 \mathrm{nM}$ ) showed higher activity in the Her-2 degradation assay in intact MCF7 cells compared to 50f $\left(\mathrm{IC}_{50}=400 \mathrm{nM}\right)$. Electron withdrawing groups in the para position had no effect on biological activity $(\mathbf{5 0 g}, \mathbf{5 0 h})$.

Treatment of $p$-chloromethylphenyl geldanamycin derivative 50b with secondary amines gave access to amides 51a-j (Scheme 10). In the series of tertiary amine-derivatives, benzylalkylamines, such as 51c, were three times more active than dialkylamines, such as $\mathbf{5 1 b}$. Comparison of the cyclic amines revealed that 4-arylpiperazines 51d-f showed superior potency over piperidine derivative $\mathbf{5 1 g}$.

Urea 52a as well as carbamates 52b-e were synthesised in an analogous fashion starting from 17-AG 48a (Scheme 11). The corresponding 17-aryl substituted geldanamycins 53a and 53b were prepared by a Suzuki cross coupling reaction under Neel's conditions using the corresponding triflates as activated geldanamycin derivatives.

Biological tests revealed that carbamate 52d (cell line Her-2: $\left.\mathrm{IC}_{50}=50 \mathrm{nM}\right)$ is the most active one within this carbamate series, while urea derivative 52a showed no antiproliferative activity.

A very large compound library covering more than sixty 17-alkylamino-17-demethoxy geldanamycin derivatives was reported by Tian et al. in 2004 (Fig. 11 and 12). It was the goal to find potent and water soluble HSP90-inhibitors. At least twenty derivatives showed cell growth inhibition potencies similar to 17-allylamino-17-demethoxygeldanamycin, 17-AAG, 15. ${ }^{98}$ In terms of water solubility one of the most promising compounds was 17-(2-dimethylaminoethyl)-amino-17-demethoxygeldanamycin (17-DMAG, 16), which was independently prepared by the NCI. In this broad SAR-screening several classes of side chains for the C-17-amino-group were investigated: a) a series of homologues to elucidate the effect of side chain size on activities $\mathbf{5 4 a - 1}$, b) a series of hydrophilic derivatives to enhance water solubility $\mathbf{5 5 a}-\mathbf{h}, \mathbf{c}$ ) a series of derivatives bearing rigid elements of branching in the side chain for improving binding affinity 16 and $\mathbf{5 6 a - g}$, d) a series of derivatives bearing substituted ethylenediamines $\mathbf{5 7} \mathbf{a}-\mathbf{p}$ and e) a series of derivatives that comprise cyclic amines at C-17 58a-f.

A two carbon linker unit appears to provide the optimal side chain length for highest antiproliferative properties towards
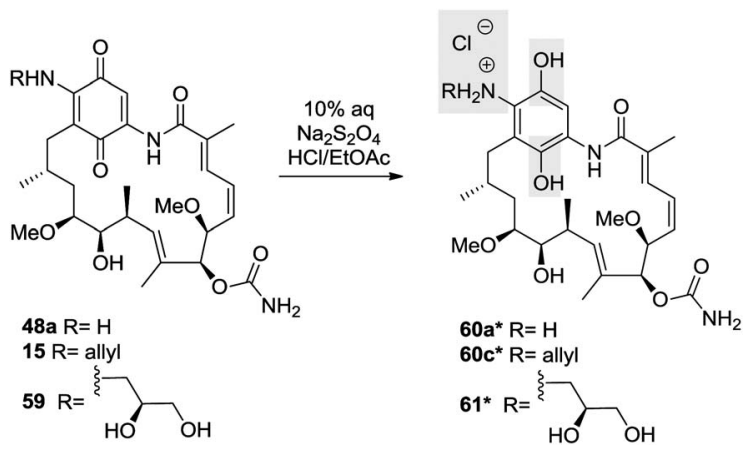

Scheme 12 Preparation of hydrochloride salts (hydroquinone form) $60 \mathbf{a}^{*}, \mathbf{b}$ * and $61 *$ 


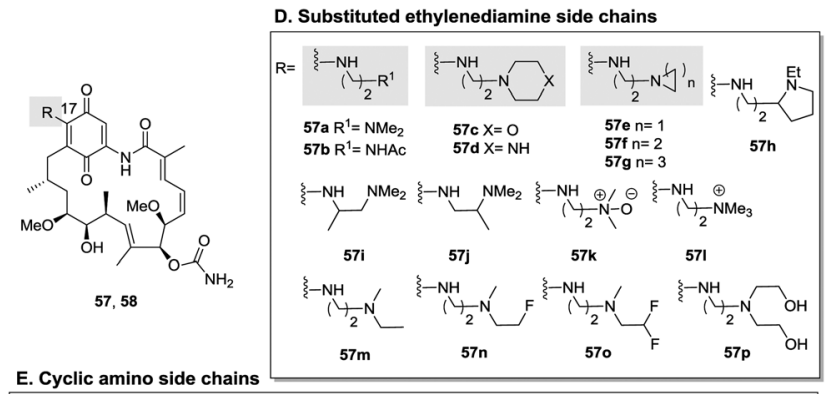

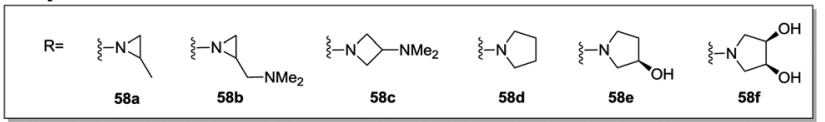

Fig. 12 Semisynthesis of geldanamycin derivatives $\mathbf{5 7}$ and $\mathbf{5 8}$ modified at C-17.

SK-Br3 cells; bulkier groups lead to reduced activities. The most significant effect is registered if the branching is located close to the amine. Substitution at the $\alpha$-position as in $\mathbf{5 4} \mathbf{i}\left(\mathrm{IC}_{50}=\right.$ $130 \mathrm{nM}$ ) furnished a marked decrease of activity compared to $\beta$-substitution as in $\mathbf{5 7} \mathbf{j}\left(\mathrm{IC}_{50}=50 \mathrm{nM}\right)$. Carboxylate $\mathbf{4 8 p}$ (see Scheme 8) was inactive and heterocyclic analogues 56d-e showed modest potency. Among the diamines, a two-carbon spacer provides the optimal side chain length, too. Thus, the potency of derivative 16a $\left(n=2 ; \mathrm{IC}_{50}=24 \mathrm{nM}\right)$ is more than 10-fold higher than 56a $\left(n=4 ; \mathrm{IC}_{50}=350 \mathrm{nM}\right)$ while binding affinities of these compounds in Hsp90-assays are similar.

Exchange of the dimethylamino group in 17-DMAG 16 by cyclic amines gave mixed results. The aziridinyl analogue 57e $\left(\mathrm{IC}_{50}=16 \mathrm{nM}\right)$ showed the highest level of cytotoxicity, followed by the azetidinyl analogue $57 f\left(\mathrm{IC}_{50}=26 \mathrm{nM}\right)$. The cytotoxicity decreases with larger ringsizes. The terminal nitrogen atom in 57a can be transformed into the corresponding $N$-oxide $57 \mathbf{k}$ or converted to a quaternary ammonium salt 571 resulting in geldanamycin derivatives forfeiting cytotoxic activities while maintaining the Hsp90 binding activities. Notably, more than twenty of the derivatives screened had $\mathrm{IC}_{50}$ values below $100 \mathrm{nM}$. At least ten of these compounds are more soluble in phosphate buffer ( $\mathrm{pH} 7$ ) than 17-AAG 15. Small linear side chains lead to an increase in cytotoxicity compared to branched chains. Another important outcome of this study is that in vitro binding to purified Hsp90 cannot generally be related to cytotoxicity. This may be rationalised if one assumes differences in drug concentrations under in vitro and in vivo conditions.

In the year 2006 Porter et al. studied highly soluble hydroquinone-hydrochloride derivatives that are related to 17-AAG 15 and some of their physiological metabolites. 17-AAG 15 was reduced to the corresponding hydroquinone by sodium hydrosulfite, which was precipitated to provide ammonium salt 60c* in high purity (Scheme 12). ${ }^{99}$ In vivo, 17-AAG 15 is readily metabolised to diol 59 and to the dealkylated analogue 17-AG 48a. These compounds were also transformed into the hydroquinone hydrochloride derivatives 60a* and 61*, respectively, that showed similar solubility and stability profiles as hydroquinone 60c*.

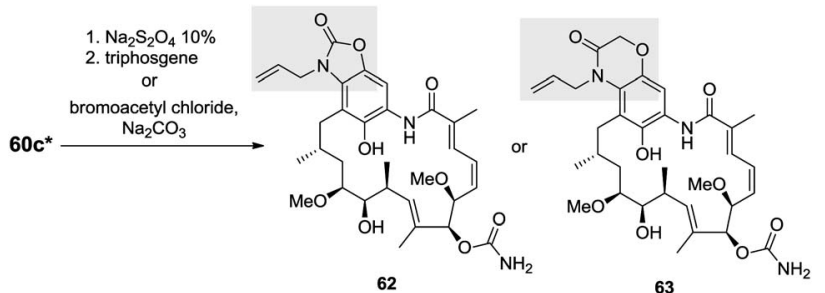

Scheme 13 Semisynthesis of locked hydroquinone derivatives $\mathbf{6 2}$ and $\mathbf{6 3}$

It was shown in cellular assays that the hydroquinone moiety is present in a redox equilibrium with the quinone. In order to prevent oxidation of hydroquinone derivative $\mathbf{6 0} \mathbf{c}^{*}$ under the conditions of the biochemical and cellular assays, Porter et al. ${ }^{99}$ locked the hydroquinone $60 \mathrm{c}^{*}$ in form of the cyclic carbamate 62 and the amide 63, respectively (Scheme 13).

Hydroquinone 60c* $\left(\mathrm{EC}_{50}=63 \mathrm{nM}\right)$ appears to exhibit a twofold higher affinity for human Hsp90 compared to the quinone $15\left(\mathrm{EC}_{50}=119 \mathrm{nM}\right)$, whereas derivatives $48 \mathrm{a}$ and 60a* (both $\mathrm{EC}_{50}=34 \mathrm{nM}$ ) essentially exerted the same affinity for Hsp90. The "locked" hydroquinones 62 and $\mathbf{6 3}$ do bind to Hsp90 but more weakly than their acyclic counterpart 60c*

Indeed, Schnur et al. demonstrated that the quinone form of geldanamycin (1) can be cleanly converted into its hydroquinone form $1^{*}$ using sodium dithionite, a process which is slowly reverted under air. However, the hydroquinone form can be stabilised after acylation and provided stable triacetate $\mathbf{6 4}$ (Scheme 14). $.4,95$

Blagg et al. attached biotin to geldanamycin via photolabile and nonphotolabile tethers, respectively (Scheme 14). The tethers incorporated both hydrophobic and hydrophilic groups. 17-Amino-derivatives 65 were prepared in the usual manner and the terminal amino group was then coupled with the biotin functionalised linker 66a or alternatively with the more hydrophilic PEG-derivatives $66 \mathrm{~b}$ or $66 \mathrm{c}$ to yield conjugates 67 and 68 ,
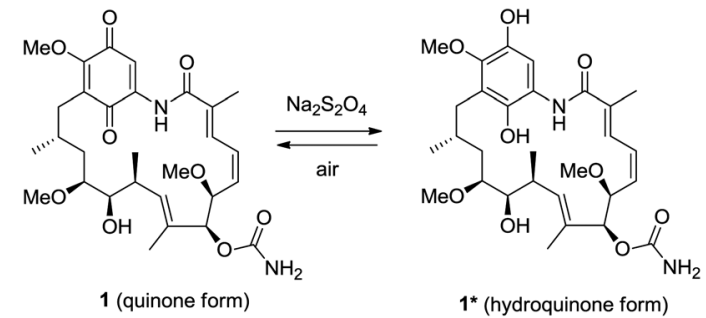

$1^{*}$ (hydroquinone form)

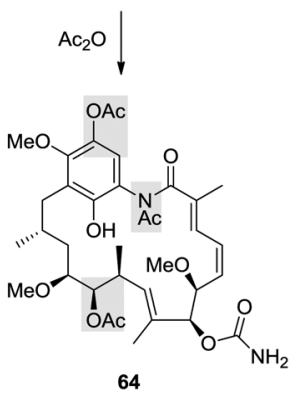

Scheme 14 Semisynthesis of stabilised hydroquinone derivative $\mathbf{6 4}$ 

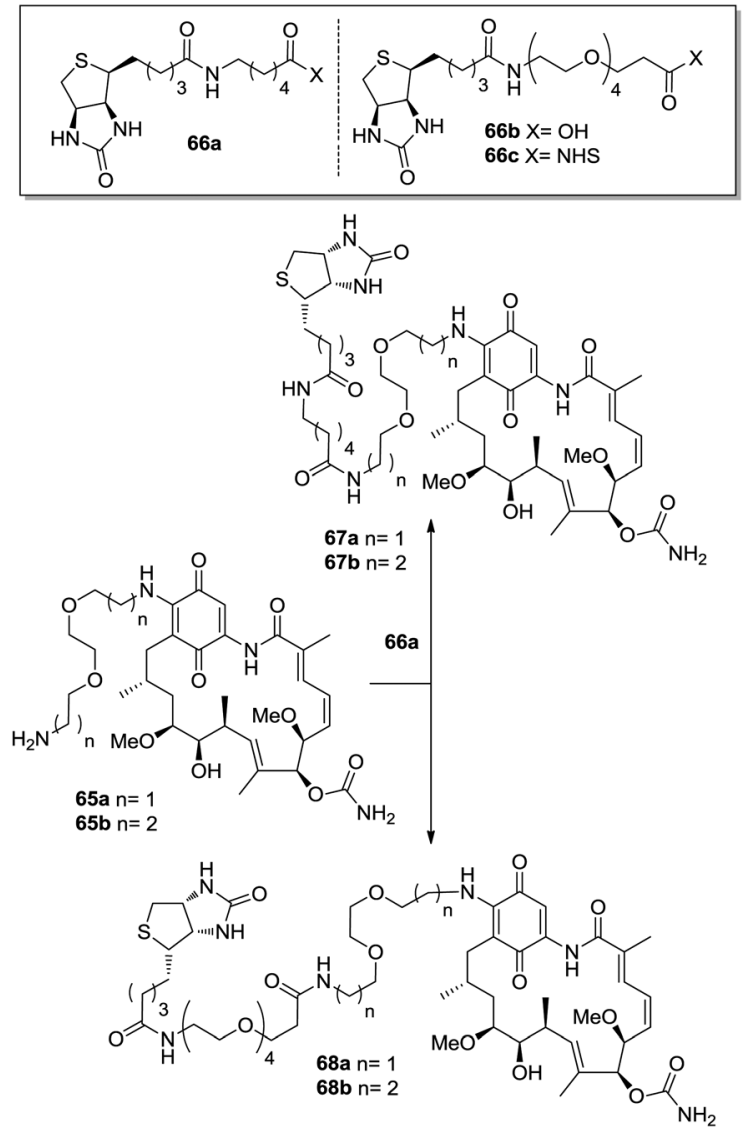

Scheme 15 Semisynthesis of biotin/geldanamycin conjugates $\mathbf{6 7}$ and $\mathbf{6 8}$.

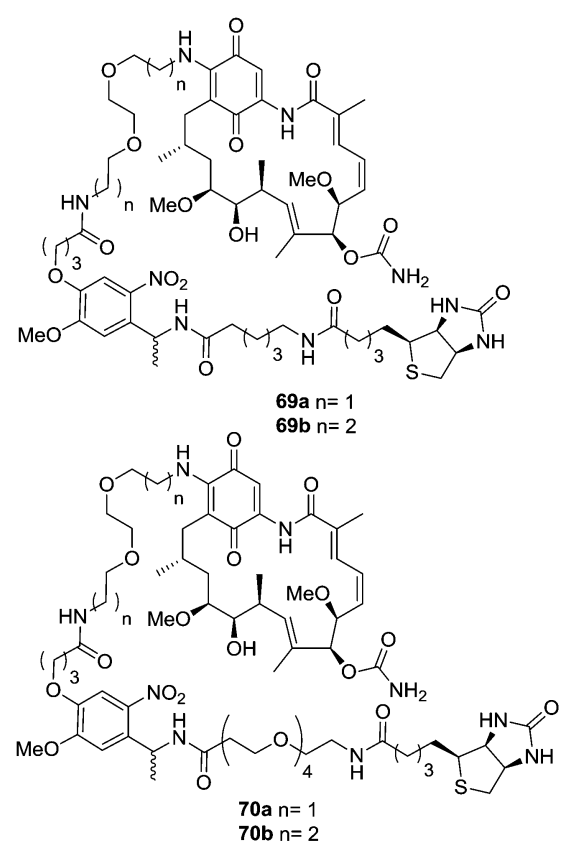

Fig. 13 Biotin derivatives $\mathbf{6 9}$ and $\mathbf{7 0}$

respectively (Scheme 15). ${ }^{100}$ Biotinylated geldanamycin conjugates 69 and 70 containing photolabile linkers were also prepared in a similar fashion (Fig. 13).
These conjugates served as biochemical tools for the development of Hsp90 assays. Incubation of 67 a with purified recombinant Hsp90 from yeast followed by affinity purification using a resin functionalised with neutravidin resulted in the capture and release of Hsp90. Incubation of 67a with Jurkat A3 proteome yielded several proteins, including Hsp90. The main goal of this assay was to search for other possible proteins binding geldanamycin and thus verifying whether geldanamycin is what is called a "dirty" drug, that targets more than one biological receptor or pathway.

In 2012 Wuest and co-workers published fluorine- and rhenium-containing geldanamycin derivatives as precursors for the corresponding ${ }^{18} \mathrm{~F}$-labeled and ${ }^{99 \mathrm{~m}} \mathrm{Tc}$-labeled molecular probes useful for imaging in vivo Hsp90 expression (Fig. 14). ${ }^{101}$

Fluorobenzoylated derivative 72a exhibited highest Hsp90 ATPase inhibitory potency comparable to geldanamycin (1). In the ATPase assay, the fluorobenzyl-functionalised geldanamycin derivative $\mathbf{7 1 b}$ and the tricarbonyl-rhenium complex $\mathbf{7 3}$ were the least active compounds while compounds $48 \mathbf{k}, 71 \mathrm{a}$ and $\mathbf{7 2 b}$ reduced ATPase activity by $50-65 \%$.

Sun et al. developed a prodrug concept for geldanamycin by preparing a galactose-geldanamycin glycoconjugate $\mathbf{7 4}$ (Fig. 15). The carbohydrate moiety is linked via $\mathrm{C}-17$ and is supposed to undergo in vivo activation by $\beta$-galactosidases thereby liberating geldanamycin derivative $\mathbf{7 5}$, which ought to bind to Hsp90 in a similar manner as 17-aminogeldanamycin 48a does. ${ }^{102}$

Using a similar concept, Wang et al. prepared a series of geldanamycin glycoconjugates $\mathbf{7 6 a - e}$ based on galactose, glucose and lactose to be used as prodrugs for enzyme activation (Fig. 16) ${ }^{103}$ Glycoconjugate 76a (cell line SW620: $\mathrm{IC}_{50}=$ $70 \mathrm{nM}$ and $\mathrm{HT}_{2} 9 \mathrm{IC}_{50}=104.7 \mathrm{nM}$ ) showed antiproliferative activity, while galactose- and lactose-derived conjugates $\mathbf{7 6 b - e}$ were all inactive. A $\beta$-glucosidase was proposed to be responsible for the unexpected cleavage of glucose in 73a, which would explain its strong antiproliferative activity.

Finally, the quinone unit can also be transformed into the 7,6-ring iminoquinone 77 as well as 5,6-fused ring systems 78 (Scheme 16). Reduction of $\mathbf{7 8 a}$ and $\mathbf{7 8 g}$ to their hydroquinones afforded unstable products that quickly yielded the quinones in the presence of air.

Most geldanamycin derivatives that are cyclised at C-17, C-18 are active; in cases of $78 \mathrm{a}\left(\mathrm{IC}_{50}=50 \mathrm{nM}\right)$, the antiproliferative activity is similar to geldanamycin (1). Even the ring enlarged
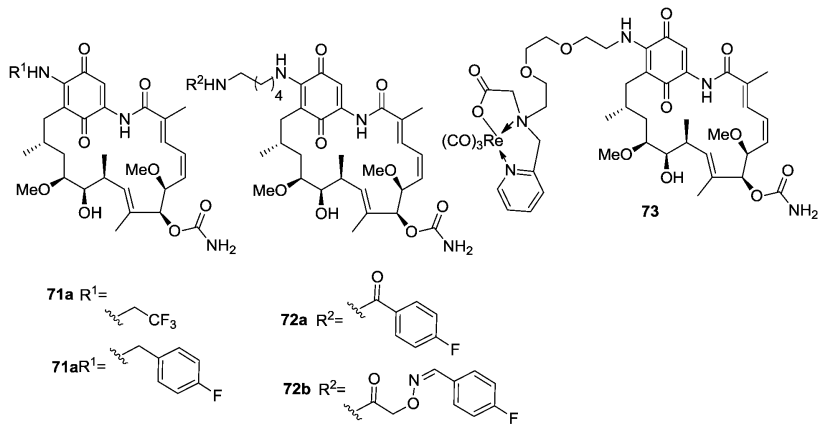

Fig. 14 Fluoro- and rhenium-functionalised geldanamycin derivatives 71-73. 


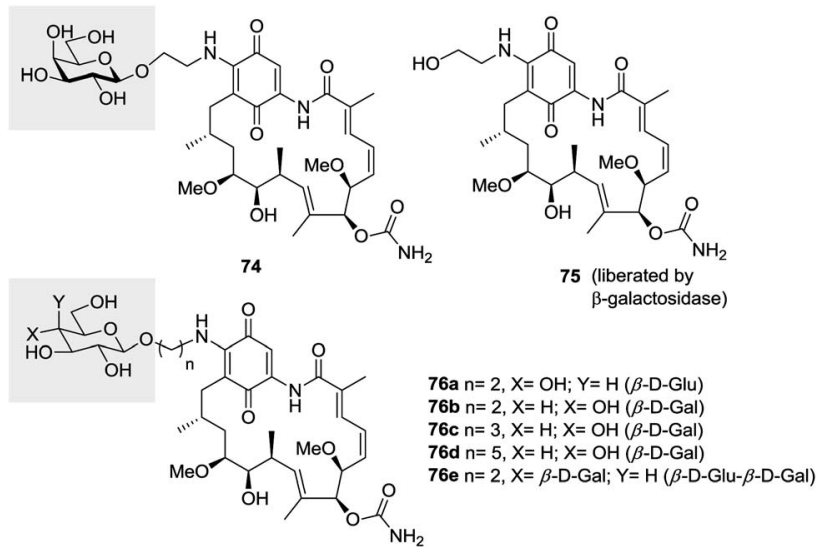

Fig. 15 Glycoconjugates $\mathbf{7 4 - 7 6}$ as potential produgs.

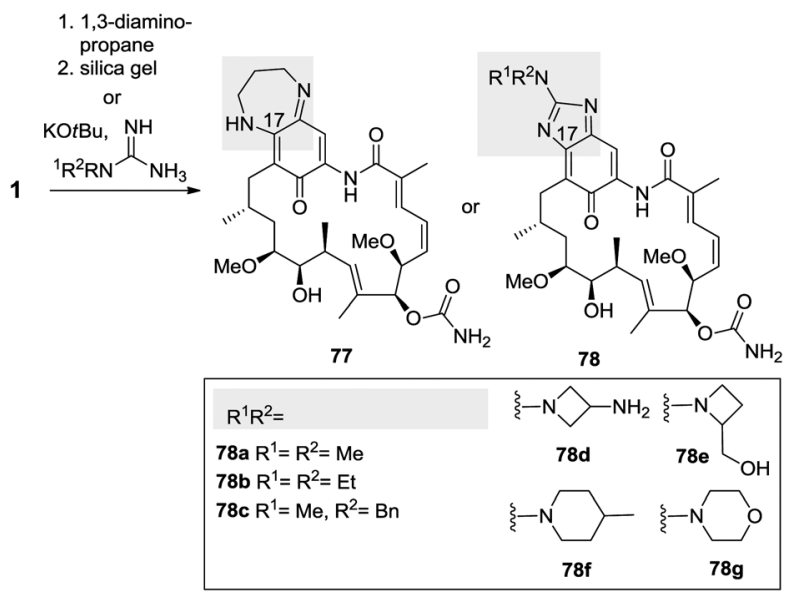

Scheme $\mathbf{1 6}$ Semisynthesis of derivatives $\mathbf{7 7}$ and $\mathbf{7 8}$

cyclic iminoquinone derivative $77\left(\mathrm{IC}_{50}=260 \mathrm{nM}\right)$ revealed in vitro potency.

5.3.2 Semisynthetic modifications in the ansa chain. Geldanamycin derivatives $\mathbf{8 4}$ modified as urea derivatives at C-7 are accessible by a two step process and it involves a [3.3]-sigmatropic rearrangement via intermediate $\mathbf{8 0}$ followed by an isothiocyanate (82 to $\mathbf{8 3}$ ) rearrangement via intermediate $\mathbf{8 2}$ (Scheme 17). Starting from semisynthetically modified geldanamycin $\mathbf{4 8 g}$ (see Scheme 9), removal of the carbamoyl group yielded 79 and from here the resulting $7(S)$-amino derivatives 84a and 84b were generated with double stereocontrol and overall retention of configuration at C-7.

An important transformation is the selective bromination at C-19 to yield bromide $\mathbf{8 5}$, which can be utilised in a similar manner as described for the preparation of the geldanamycin derivatives 86. Here, the addition-elimination mechanism is favoured for the bromide because of its better nucleofugic properties compared to the methoxy group at C-17. With selected amines geldanamycin derivatives 86a and 86b were obtained (Scheme 18). When incorporating substituents at C-19 a strong reduction of antiproliferative activity takes place (see 86a,b).
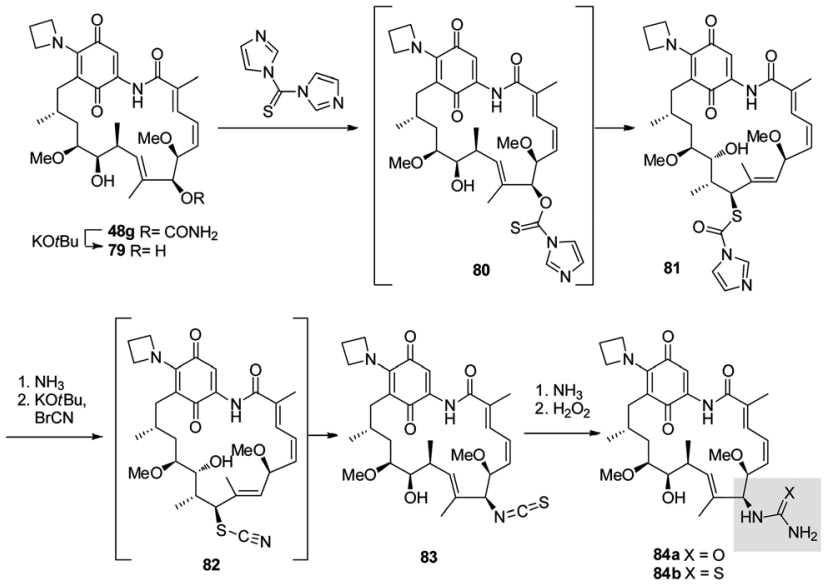

Scheme 17 Semisynthesis of C-7 urea analogues $\mathbf{8 4 a}$ and $\mathbf{8 4 b}$.

Schnur et al. also pursued semisynthetic changes on the straightforwardly accessible functional groups of the ansa-ring. Geldanamycin and 4,5-dihydro derivative $\mathbf{4 8}$ and $\mathbf{4 6}$ served as a starting point for further changing the macrolactam nitrogen atom as well as the hydroxyl group at C-11 (Schemes 19-23). Thus, $\mathrm{N}$-substituted derivatives $\mathbf{8 7} \mathbf{a}-\mathbf{k}$ and $\mathbf{8 8}, 11-\mathrm{O}$-acyl products 89a-g, 7-deamidinated analogues 90a,b, esters 91a-c, 7-keto-analogue 92, 11-keto-derivatives 93a-b and 93d, 11oximes 94a-b, 11-amino derivatives 95a-b and 11-(S)-fluoro derivatives 96a-d were accessed by Schnur et al. ${ }^{104}$

These studies demonstrated that 17-azetidine and 17-allylamino-derivatives are among the most potent $\mathrm{C}-17$ analogues. Still, the lowest $\mathrm{IC}_{50}$ were determined for the free amino derivatives such as aminogeldanamycine derivatives $87 \mathbf{f}\left(\mathrm{IC}_{50}=\right.$ $230 \mathrm{nM}$ ) compared to $87 \mathbf{k},\left(\mathrm{IC}_{50}=1900 \mathrm{nM}\right) . N$-Pyridylmethyl derivative $\mathbf{8 7} \mathbf{j}$ was $>100$ fold less potent than analogues bearing a carbonyl group in the $\alpha$-position of the $N$-alkyl group (e.g. 87a or $87 \mathbf{i}$, respectively). Phenacyl-analogues $87 \mathbf{b}\left(\mathrm{IC}_{50}=80 \mathrm{nM}\right)$ and $87 \mathbf{j}\left(\mathrm{IC}_{50}=70 \mathrm{nM}\right)$ show similar antiproliferative activity to geldanamycin $(\mathbf{1})\left(\mathrm{IC}_{50}=70 \mathrm{nM}\right)$.

Acylation of the hydroxyl group at C-11 (Scheme 20) could also be achieved and provided new derivatives 89a-g with similar biological activities compared to their unsubstituted precursors.

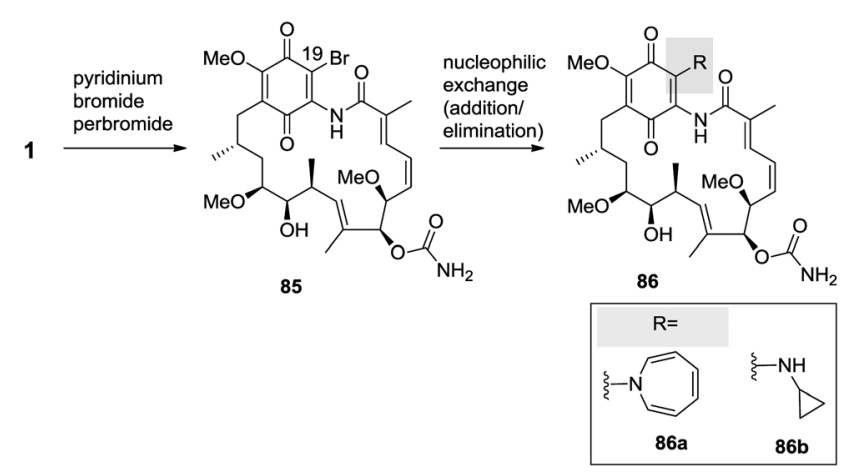

Scheme 18 Semisynthesis of C-19 modified quinone derivatives $\mathbf{8 6 a}$ and $\mathbf{8 6 b}$. 

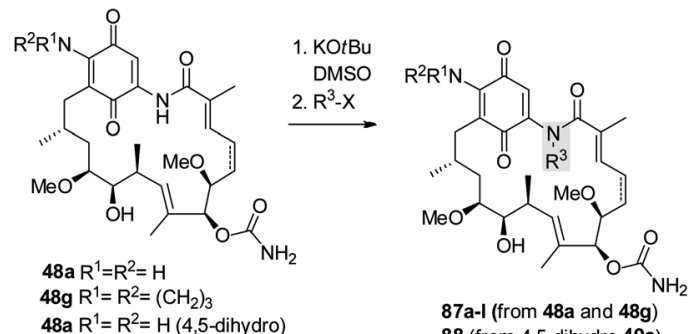

48a $R^{1}=R^{2}=H(4,5-$ dihydro $)$

$87 \mathrm{a}-1$ (from $48 \mathrm{a}$ and $48 \mathrm{~g}$ ) 88 (from 4,5-dihydro 49a)

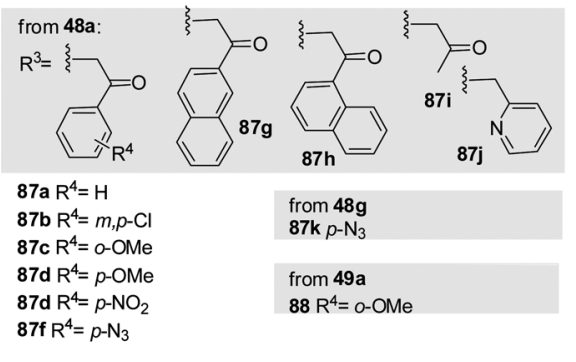

Scheme $\mathbf{1 9}$ Semisynthesis of geldanamycin derivatives $\mathbf{8 7 a} \mathbf{- k}$ and $\mathbf{8 8}$.
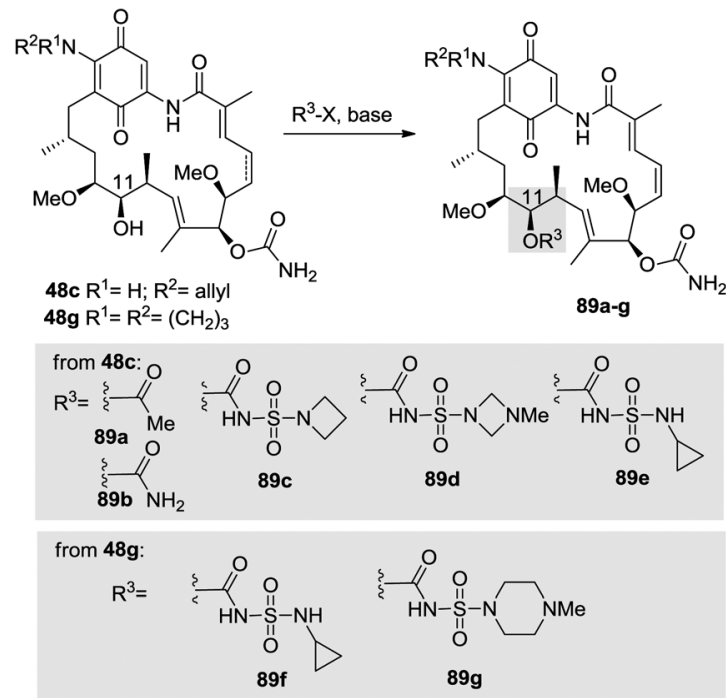

Scheme $\mathbf{2 0}$ Semisynthesis of geldanamycin derivatives $\mathbf{8 9} \mathbf{a} \mathbf{- g}$

Removal of the amidinoyl group gave geldanamycin derivatives 79 and 90a,b; both have lost their biological activity. The same change of biological properties occurred, when the amidinoyl group was exchanged by other acyl groups at $\mathrm{C} 7$ as in geldanamycin derivatives 91a-c or after oxidation of C-7, as in 92 (Scheme 21). Clearly, the free carbamoyl group acts as a pharmacophore. It is suggested that Asp40 and Lys44 in the ATP-binding domain of Hsp90 are essential for binding of the quinone moiety of geldanamycin.

Specific exchange of selected amino acids in the highly conserved ATP-binding site (Lys44 by arginine and Lys89 by aspartate) suggest they stabilise the quinone ring. Other important positions that have an effect on geldanamycin binding are Glu88 (demonstrated by exchange with glycine) and

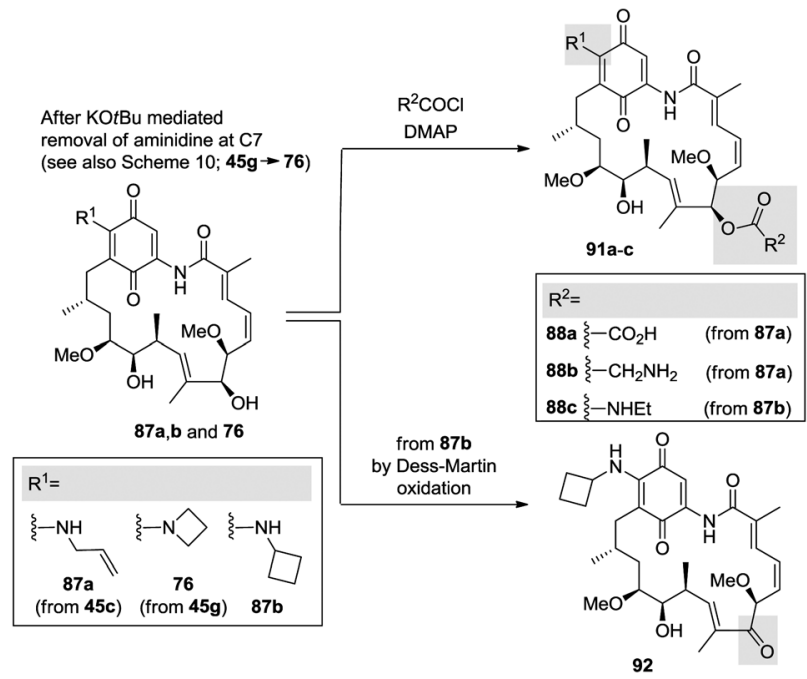

Scheme 21 Semisynthesis of derivatives $\mathbf{9 1 a - c}$ and $\mathbf{9 2}$.

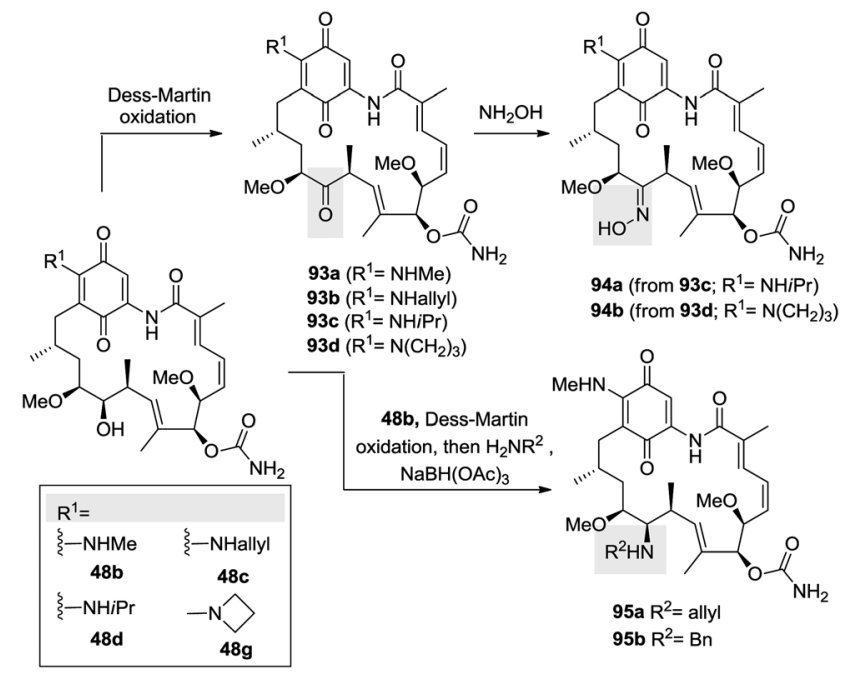

Scheme 22 Semisynthesis of C-11-derivatives $\mathbf{9 3 a - d , ~ 9 4 a , b}$ and $\mathbf{9 5 a} \mathbf{a} \mathbf{b}$

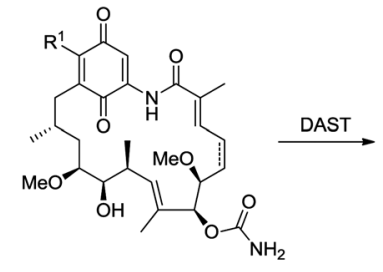

48 or 49 (4,5-dihydro)
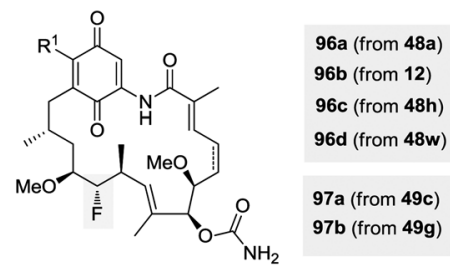

$\mathrm{R}^{1}=$

$\xi-\mathrm{NH}_{2} \xi-\mathrm{NHallyl}$

48a 12

$\xi-\mathrm{N}\left(\mathrm{CH}_{2}\right)_{3} \underset{2}{\mathrm{HN}} \longrightarrow$

$48 \mathrm{~h} \quad m_{n}^{\prime} 48 \mathrm{w}$

Scheme $\mathbf{2 3}$ Semisynthesis of fluorinated geldanamycin derivatives $\mathbf{9 6 a - d}$ and 97a,b. 
Asp92 (demonstrated by exchange by leucine). ${ }^{104 c, \boldsymbol{d}}$ Double exchange mutations (Lys44 by arginine and Lys 89 by asparagine) in the yeast chaperon homologue Hsp82 did result in decreased sensitivity towards $17-\mathrm{AAG} 12$, perhaps due to weakened binding to the C-12 methoxy group on (1). ${ }^{\mathbf{1 2 2}}$

Oxidation of the hydroxyl group at $\mathrm{C}-11$ yielded ketones $93 \mathrm{a}$ $\left(\mathrm{IC}_{50}=220 \mathrm{nM}\right)$ and $93 \mathrm{~b}\left(\mathrm{IC}_{50}=34 \mathrm{nM}\right)$ and $93 \mathrm{c}\left(\mathrm{IC}_{50}=34 \mathrm{nM}\right)$, all of which showed superior potency to the oximes $94 \mathrm{a} / \mathrm{IC}_{50}=$ $270 \mathrm{nM})$ and 94b $\left(\mathrm{IC}_{50}=1100 \mathrm{nM}\right)$. Reductive amination afforded amino derivatives 95a and 95b, respectively, which were less active than both the corresponding alcohols and the ketones.

An interesting semisynthetic transformation allows the introduction of a fluoro substituent at C-11 with inversion of configuration using diethylaminosulfur trifluoride (DAST). In vivo studies revealed that two of the four new fluorinated derivatives, namely $96 \mathrm{a}\left(\mathrm{IC}_{50}=46 \mathrm{nM}\right)$ and $96 \mathrm{~b}\left(\mathrm{IC}_{50}=50 \mathrm{nM}\right)$ showed very good antiproliferative activity. These in vivo studies are noteworthy, because many new geldanamycin derivatives obtained by semisynthesis showed hardly any in vivo

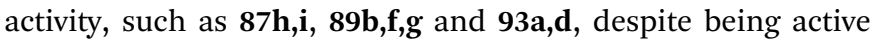
in vitro.

Rastelli et al. also prepared geldanamycin derivatives that varied at C-7 (Scheme 24). The carbamoyl group is integrated in a hydrogen bonding network that involves four water molecules. By modifying the substituent at C-7 insight into the importance of this network was gained. Saponification of the carbamoyl moiety followed by reaction with carbodiimidazole (CDI) and trapping of the CDI-adduct with nucleophiles (hydrazine, hydroxylamine) furnished new $7-N$-alkyl-carbamates 98a-o. ${ }^{105}$ The majority of these derivatives showed no biological activity and only low Hsp90 affinity. Only $\mathbf{9 8 f}-\mathbf{k}$ and $\mathbf{9 8 m}$ were active towards SK-Br3 cells in the range of around $0.5 \mu \mathrm{M}$.

\subsection{Geldanamycin derivatives by manipulation of its biosynthesis}

Over the past decade, the combination of metabolic engineering of biosynthetic pathways that code for secondary
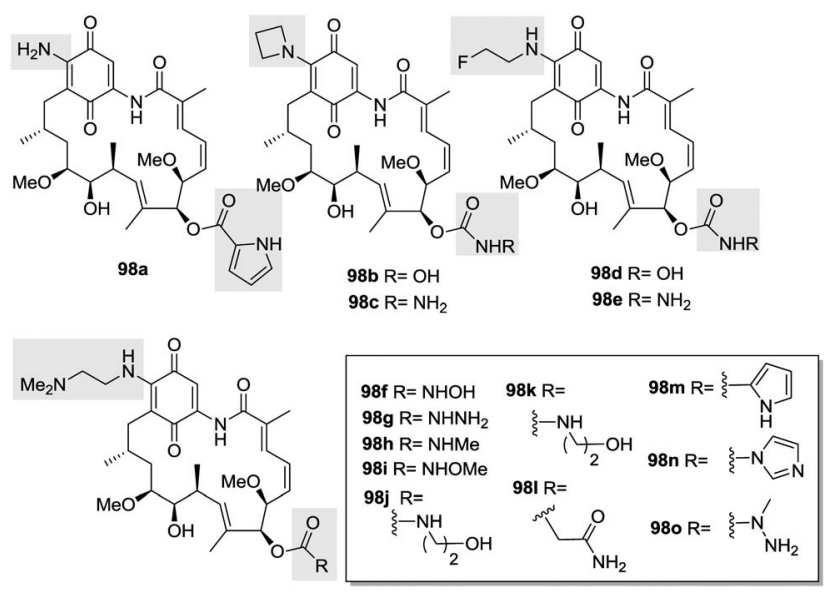

Scheme 24 Semisynthesis of C-7-derivatives 98a-o. metabolism with semisynthetic modifications has emerged as a powerful tool for the creation of derivatives of structurally complex natural products that are difficult to access otherwise. The preciseness of the biosynthetic machinery that is able to construct complex frameworks and macrocycles in a rather linear fashion meets chemical synthesis with its enormous flexibility for introducing functional groups, including pharmacophoric ones that are unprecedented in nature.

5.4.1 Exchange of individual enzymes by genetic engineering. Due to its pharmaceutical importance the biosynthesis of the heat shock protein inhibitor geldanamycin was studied in detail, ${ }^{\mathbf{1 0 6}}$ allowing initiation of different metabolic engineering programs with the aim to generate geldanamycin derivatives.

Kosan Biosciences, Inc disclosed an elegant strategy that relied on the genetic manipulation of the geldanamycin polyketide synthase (GdmPKS) Streptomyces hygroscopicus ${ }^{\mathbf{1 0 7}}$ that provided several new derivatives lacking methyl or methoxy groups in the ansa chain. ${ }^{108}$ The strategy is based on the substitution of acyltransferase (AT) domains in six different GdmPKS modules that commonly accept methylmalonyl-CoA or methoxymalonyl-CoA, by malonyl AT domains from the rapamycin PKS. ${ }^{109}$ Overall this engineering of the biosynthesis provided 2-desmethyl, 6-desmethoxy, 8-desmethyl, and 14-desmethyl geldanamycin derivatives $\mathbf{9 9 - 1 0 2}$, as well as the $\gamma, \delta$-saturated 103 and the hydratisation products 104 and 105 in sufficient amounts (Scheme 25).

Tian and Rastelli noted that Hsp90 binding is not a predictive indicator for cytotoxicity. The Hsp90 binding affinity of phenol $102\left(\mathrm{IC}_{50}=860 \mathrm{nM}, \mathrm{K}_{\mathrm{d}}(\mathrm{Hsp} 90)=16 \mathrm{nM}\right)$ is 4 -fold higher than of geldanamycin $1\left(\mathrm{IC}_{50}=41 \mathrm{nM}, K_{\mathrm{d}}(\mathrm{Hsp} 90)=670 \mathrm{nM}\right)$ though the antiproliferative activity is much smaller. Furthermore, the high binding affinity of $\mathbf{1 0 2}$ reveals that the quinone group has little significance for the observed hepatotoxicity of geldanamycin (1). Derivatives $99\left(\mathrm{IC}_{50}=470 \mathrm{nM}\right)$ and 100 $\left(\mathrm{IC}_{50}=480 \mathrm{nM}\right)$ exhibit moderate biological activity while $101\left(\mathrm{IC}_{50}=3200 \mathrm{nM}\right), 103\left(\mathrm{IC}_{50}=4900 \mathrm{nM}\right)$ and $104\left(\mathrm{IC}_{50}=\right.$ $>5000 \mathrm{nM}$ ) exerted no cytotoxicity.

5.4.2 Blocking of selected enzymes by genetic engineering. In work by Zhang et al. macbecin (3) served as lead structure for Hsp90 inhibition. By genetic engineering, mutants were created that are blocked in selected oxidative tailoring steps of macbecin biosynthesis. These mutant strains yielded novel macbecin analogues like the nonquinone compounds 105 and 106b with significantly improved binding affinity to Hsp90 $\left(K_{\mathrm{d}}=3 \mathrm{nM}\right.$ vs. $240 \mathrm{nM}$ for macbecin) and reduced toxicity (MTD $>$ or $=$ $250 \mathrm{mg} \mathrm{kg}^{-1}$ ) (Fig. 16). The authors speculated that enhanced structural flexibility allows more facile preorganisation in the Hsp90-bound conformation in solution. ${ }^{\mathbf{1 1 0}}$

Hong and coworkers followed a similar approach. Site directed mutagenesis of the geldanamycin polyketide synthase (PKS) and selected post-PKS tailoring genes provided several C-15 hydroxylated non-quinone geldanamycin analogues. One new derivative, 15-hydroxy-17-demethoxy analogue 107, exhibited stronger inhibition of Hsp90 ATPase activity by a factor of almost five than geldanamycin. ${ }^{111}$ 

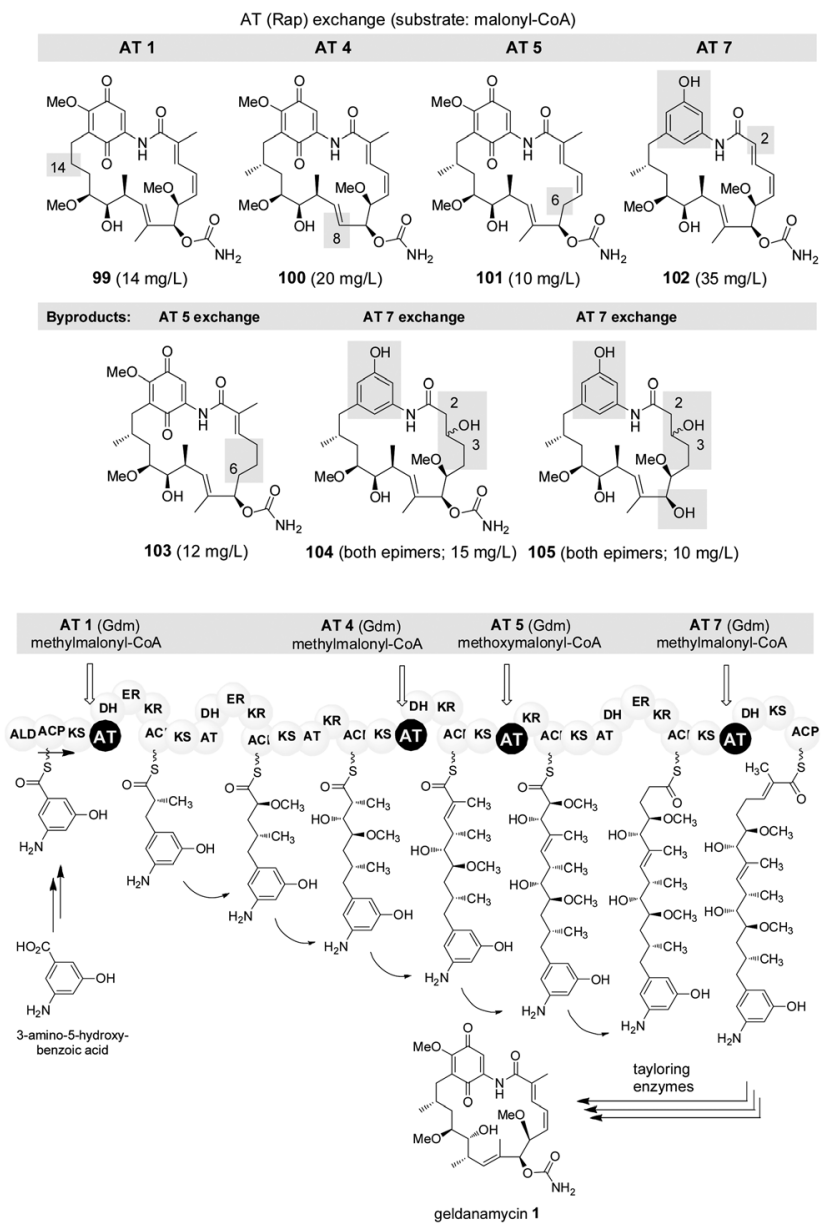

Scheme 25 Geldanamycin derivatives $\mathbf{9 9 - 1 0 5}$ produced by acyltransferase (AT) substitutions in the Gdm polyketide synthase (numbers refer to PKS module; areas marked in grey show structural variations with respect to geldanamycin (1)).
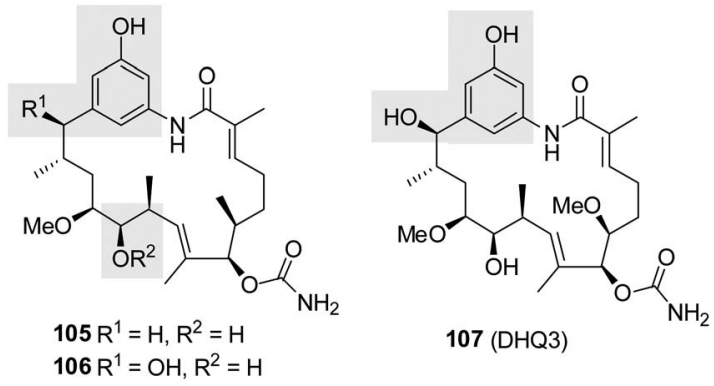

Fig. 16 New phenolic geldanamycin derivatives isolated from mutant strains modified by site directed mutagenesis in selected tailoring biosynthetic steps.

5.4.3 Mutasynthetic approaches. Hong et al. also used a semisynthetic approach that utilised the product obtained from a genetically engineered organism. ${ }^{112}$ A mutant strain from Streptomyces hygroscopicus subsp. duamyceticus (JCM4427), which lacked the active carbamoyltransferase, provided geldanamycin derivative $\mathbf{1 0 8}$ as the main fermentation product. Obviously, genetic interference also blocked the last biosynthetic step leading to the desaturation at C-4,C-5. The missing carbamoyl group renders this metabolite biologically inactive (see above). Next, this 4,5-dihydro geldanamycin derivative 108 was treated with trichloroacetyl isocyanate to yield bis-carbamoyl derivative 110. This compound was treated with various amines to introduce an amino substituent at C-17 (see also Scheme 8) to provide 4,5-dihydro derivatives 112a-d. For comparison purposes also the 17-aminated 7,11-bis-carbamoylderivatives 111a,c-e were chemically prepared from geldanamycin (1) via 109 (Scheme 26).

As expected compound $\mathbf{1 0 8}$ is inactive as opposed to carbamoylated 4,5-dihydrogeldanamycin 47. The C-7,11-bis-carbamates 112a-d carrying an aminoalkyl substituent at C-17 exert a broad scope of antiproliferative activities. 112c (cell line SK-Br3: $\mathrm{IC}_{50}=0.32 \mu \mathrm{M}$ and cell line SK-Ov3: $\left.\mathrm{IC}_{50}=5.09 \mu \mathrm{M}\right)$, and 112d (SK-Br3: $\mathrm{IC}_{50}=0.01 \mu \mathrm{M}$ and SK-Ov3: $\left.\mathrm{IC}_{50}=1.14 \mu \mathrm{M}\right)$ exhibit improved potency compared to 4,5-dihydro derivative 11 (SKBr3: $\mathrm{IC}_{50}=3.07 \mu \mathrm{M}$ and SK-Ov3: $\mathrm{IC}_{50}=7.90 \mu \mathrm{M}$. Still, in comparison to geldanamycin $\left(\mathrm{IC}_{50}=70 \mathrm{nM}\right)$ and the geldanamycin derivatives 111a (SK-Br3: $\mathrm{IC}_{50}=0.05 \mu \mathrm{M}$ and SK-Ov3: $\left.\mathrm{IC}_{50}=6.97 \mu \mathrm{M}\right)$, as well as 111c (SK-Br3: $\mathrm{IC}_{50}=0.020 \mu \mathrm{M}$ and SK-Ov3: $\left.\mathrm{IC}_{50}=0.67 \mu \mathrm{M}\right)$, the corresponding 4,5-saturated compounds 112a (SK-Br3: $\mathrm{IC}_{50}=>10 \mu \mathrm{M}$ and SK-Ov3: $\mathrm{IC}_{50}=$ $10.52 \mu \mathrm{M})$ and 112c $\left(\mathrm{SK}-\mathrm{Br} 3: \mathrm{IC}_{50}=0.32 \mu \mathrm{M}\right.$ and SK-Ov3: $\mathrm{IC}_{50}=$ $5.09 \mu \mathrm{M}$ ) carrying an additional carbamoyl group at C-11, were less potent.

Treatment of 4,5-dihydro derivative 108 with diketene generated bis-diketo-derivative 113, which was inactive in antiproliferative tests (Scheme 26). This result fits well with the

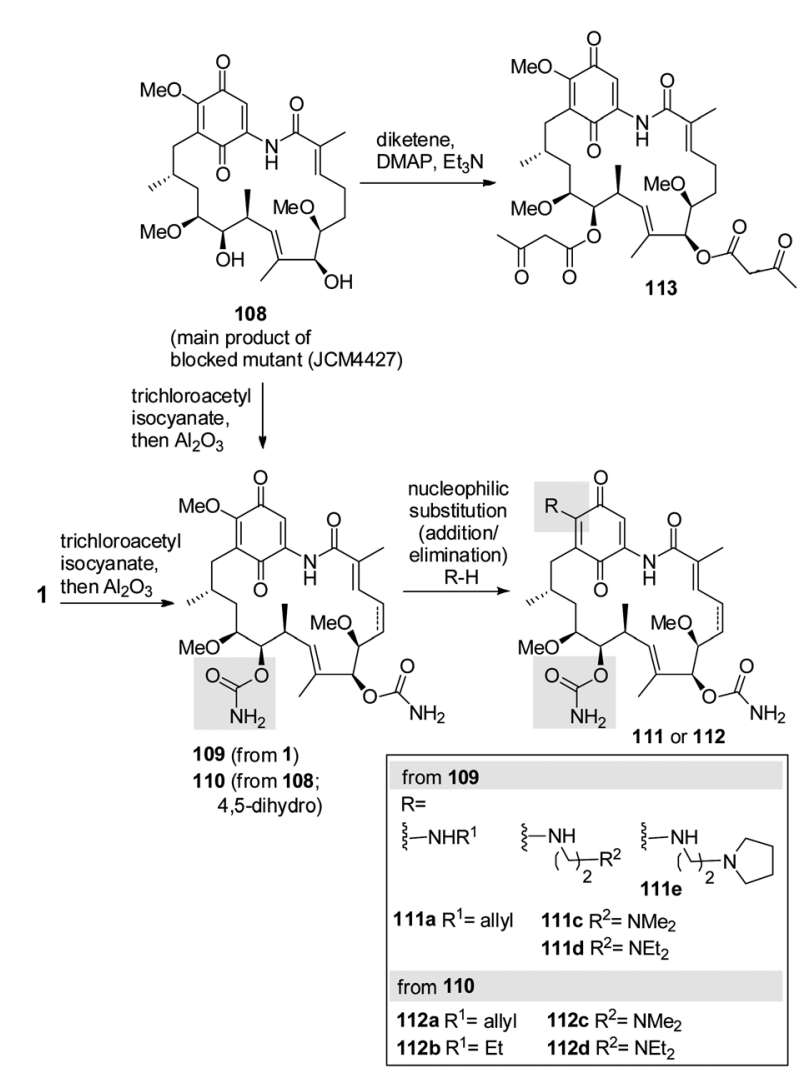

Scheme 26 Semisynthesis of C-17 amino analogues $\mathbf{1 1 1 a , c - e , ~ 1 1 2 a - d ~ a n d ~} \mathbf{1 1 3}$. 
observations from semisynthetic studies towards similar derivatives like 91.

Several groups employed mutant strains of $S$. hygroscopicus that are specifically blocked in the biosynthesis of the PKS starter building block 3-amino-5-hydroxybenzoic acid (see Scheme 25) in order to exploit the concept of mutational biosynthesis (mutasynthesis). ${ }^{83}$ By supplementing a culture of this mutant strain with different chemically modified amino benzoic acids 114 and 115 Menzella and coworkers ${ }^{113}$ as well as Lee and Hong ${ }^{114,115}$ isolated a series of new geldanamycin derivatives 120a-c and 121a,b in sufficient amounts for structural analysis and biological evaluation (Scheme 27). Likewise Kirschning et al. ${ }^{116}$ could prepare new geldanamycin derivatives 122-125 after supplementing a culture of the AHBA blocked mutant of $S$. hygroscopicus with mutasynthons 116-119. Remarkably, also the pyridine precursor 126 was accepted and processed to the aza-geldanamycin derivative 127.

Cell growth inhibition assays for $\mathbf{1 2 0}$ and $\mathbf{1 2 1}$ demonstrated activities similar to those of tanespimycin $\mathbf{1 5}$ and alvespimycin 16 against a panel of cancer cell lines. Also new geldanamycin derivatives 122-125 showed strong antiproliferative activity, most of them having $\mathrm{IC}_{50}$ values in the $\mathrm{nM}$ range. Remarkably, the fluoro and bromo derivatives $123\left(\mathrm{IC}_{50}: 18-73 \mathrm{nM}\right)$ and 122 $\left(\mathrm{IC}_{50}: 17-120 \mathrm{nM}\right)$ turned out to be as active as geldanamycin. In contrast, aza-geldanamycin $\mathbf{1 2 7}$ was inactive in assays determining antiproliferative activity.

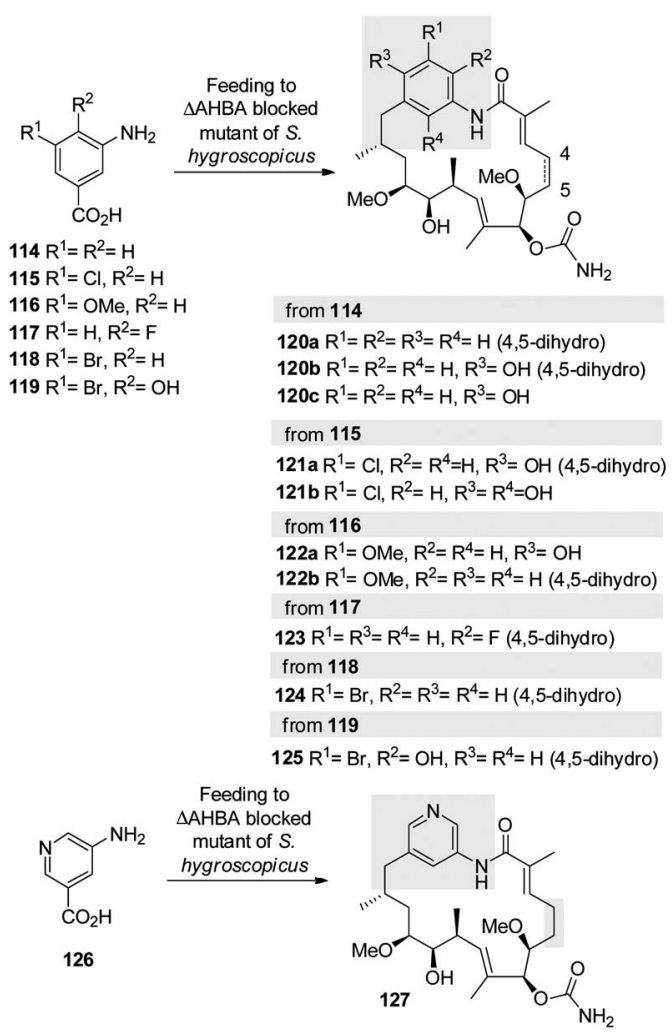

Scheme 27 Mutasynthetic preparation of geldanamycin derivatives 120-125 and 127.
Mutasynthon 128 provided a remarkable number of differently processed geldanamycin derivatives being fed to the AHBA blocked mutant of $S$. hygroscopicus. Besides the expected products 129 and 130, the blocked mutant strain also provided 20membered macrolactones 133a-c. Obviously, the benzyl alcohol competes as a nucleophilic function with the anilino group for the PKS-bound seco acid during amide synthase-promoted macrocyclisation. These results were further generalised by feeding benzoic acids 131 and 132 containing an additional benzyl alcohol which resulted in the formation of macrolactones 134 and 135, respectively (Scheme 28). ${ }^{117}$

Geldanamycin derivatives $129 b$ and $129 c$ and $130 b$ showed good $\left(130 \mathrm{~b} \mathrm{IC}_{50}=22-470 \mathrm{nM}\right)$ to moderate antiproliferative activities towards different cancer cell lines while 129a and 130a were $>100$ fold less potent than geldanamycin (1). The 20membered lactones 133a-c, 134 and 135 exhibited no antiproliferative properties or Hsp90 binding affinity at all.

\section{Assaying inhibitory effects on Hsp90 function by high throughput screening}

The rising demand for compound libraries has led to the development of fully automated high-throughput screening devices (HTS). Test protocols in pharmaceutical industry are commonly target-oriented, i.e. the interaction of a test compound with a biological target is investigated. The HTS results are analysed in a statistical manner and a positive assay response is called a "hit". Clearly, the quality of HTS-derived results are associated with too many false positive responses from which the few true leads have to be found by laborious deconvolution. In addition, no statement on pharmacokinetics of the "hit", such as toxicity, membrane permeability and solubility of the identified substance, is possible at this stage. The typical HTS setup utilises the microplate format for assaying and trailing target-inhibitor complexes. It commonly relies on a biochemical reaction in which a substrate is functionalised with a radioactive or fluorescent label. For identifying potential inhibitors for Hsp90, various methods are known for how HTS can be performed. These are a) cell-based assays, b) refolding assays and c) binding assays. The classical cell-based assay addresses antiproliferation

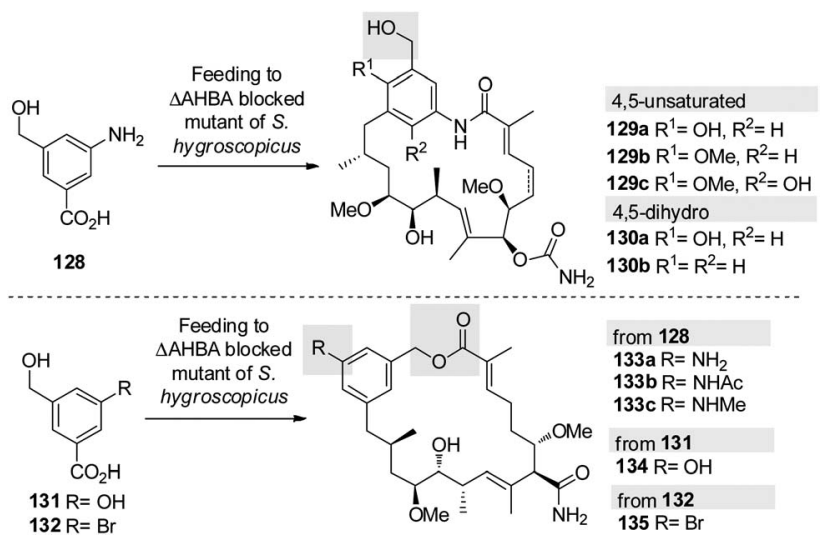

Scheme 28 Mutasynthetic preparation of geldanamycin derivatives 129, 130 and 133-135. 


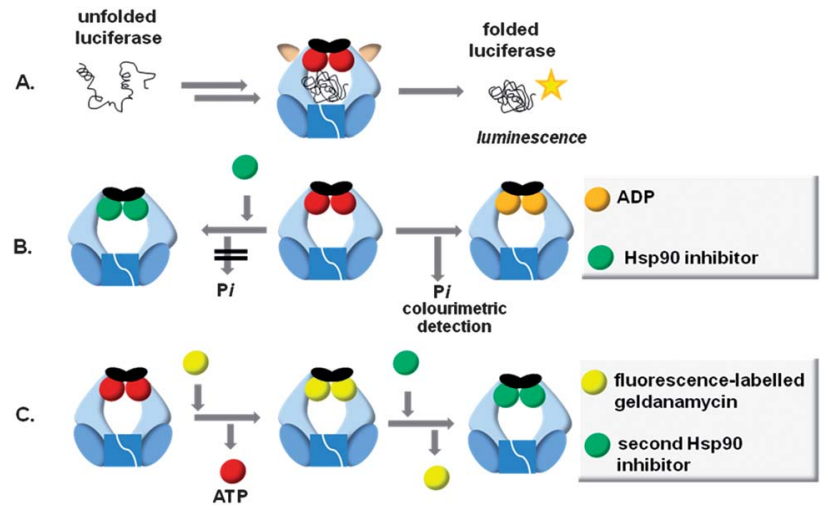

Fig. 17 A graphical presentation of the principal Hsp90 assays (A. folding assay; B. ATPase activity assay; C. fluorescence polarization assay; for graphical details also refer to Fig. 5 and 6).

and combines activity and selectivity. ${ }^{117}$ The folding assay addresses the function of Hsp90 as a molecular chaperone (Fig. 17A). Here, the enzyme luciferase is employed. It catalyses the oxidation of luciferin to unstable oxyluciferin and its decay is monitored as a chemiluminescence signal. ${ }^{118}$ In this assay the capability of Hsp90 to refold heat denatured luciferase to an active luciferase form is exploited. In the presence of Hsp90 inhibitors inhibition of chaperone function is observed, leaving luciferase denatured. The loss of chaperone function correlates with the decrease of chemiluminescence.

Another type of assay, the specific binding of a potential inhibitor and Hsp90, is being investigated. In this context various methods have been developed. These include the ATPase activity assay (Fig. 17B), the proteolytic fingerprint assay combined with mass spectrometry, the thermal shift assay, fragment screening using affinity capillary electrophoresis (CEfrag), surface plasmon resonance (SPR), thermophoresis, the fluorescence polarisation technique and TIRF (total internal reflection fluorescence). This latter technique is well-suited for analysis of biomolecular interactions and mechanistic studies of biomolecular events. Finally, the Alpha (Amplified Luminescent Proximity Homogeneous Assay) Screen is a very sensitive non-radioactive homogeneous, but expensive assay technology that allows the screening of interaction on a high accuracy level using donor and acceptor beads. ${ }^{13 b, 15,58,119,120}$ Formats suitable for a colorimetric quantification are also frequently used; in the case of Hsp90 this is achieved by detecting inorganic phosphate as a phosphomolybdate complex. ${ }^{121 a}$ Fluorescence polarisation utilises a geldanamycin derivative as Hsp90 inhibitor that is labeled with fluorescein isothiocyanate (FITC) (Fig. 17C).

Microscale thermophoresis (MST) is a novel technique that allows the characterisation of biomolecules in a label-free fashion. The method is able to detect changes in thermophoretic mobility induced by ligand binding. Several factors such as size, charge and solvation entropy influence the mobility of the biomacromolecule and it has been shown that this is a highly sensitive technique to distinguish between binding and nonbinding. ${ }^{121 b, c}$

The use of these assays as well as cell growth test provided a detailed overview on the structure-activity relationships (SAR) of geldanamycin (1) as a lead structure. The previous chapter not only gave a detailed summary of how libraries of analogues have been prepared but also provided information on antiproliferative activity for most derivatives. Indeed, more than 500 geldanamycin derivatives have been reported to be assayed up to date. A qualitative conclusion of these structure-activity relationship studies can be drawn and consequently a "SAR map" can be created that is depicted in Fig. 18.

\section{Outlook}

Geldanamycin has emerged as a show case tool for unraveling a new mechanism of cell biology (Hsp90) and establishing it as a new biological target with therapeutic relevance. The penicillins (bacterial transpeptidase) and paclitaxel $\left(\mathrm{Taxol}^{\circledR}\right.$ ) (polymerisation of tubulin) are other famous natural product examples that were starting points for target driven pharmaceutical research programs. In the case of Hsp90, the natural products novobiocin (9) and radicicol (13) accompanied this profound interest in cell biology and biochemistry of heat shock proteins. Geldanamycin (1) and radicicol (13) have become lead structures for cancer driven research on Hsp90. Several geldanamycin analogues are in clinical trials, such as 17-AAG 15, the corresponding hydrochloride salt 136 (Bristol-Myers Squibb) and amino geldanamycin 48a (Infinity Pharmaceuticals) (Fig. 19). Radicicol (13) is structurally simpler than geldanamycin and typical medicinal chemistry programs provided new derivatives 137 (Novartis), 138 (Kyowa Hakko Kirin Co., Ltd) and 139 (Synta Pharmaceuticals Corp.) with strong anticancer activities based on Hsp90 inhibition. ${ }^{122}$

So far, no Hsp90 inhibitor has reached commercialisation and it remains to be seen whether an Hsp90 inhibitor will ever be a drug. Future developments may have to investigate the contribution of Hsp90 paralogues to the observed activity of these established inhibitors. Indeed, first results indicate that there could be applications of Hsp90 inhibitors beyond cancer.

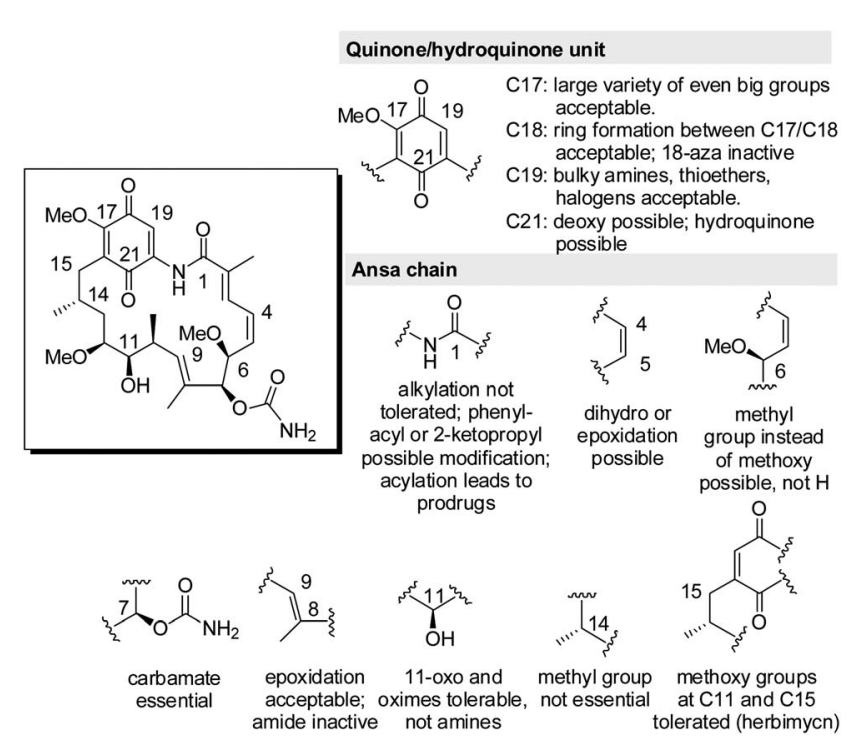

Fig. 18 A "SAR-map" of geldanamycin as a lead structure. 
Geldanamycin (1) as lead structure

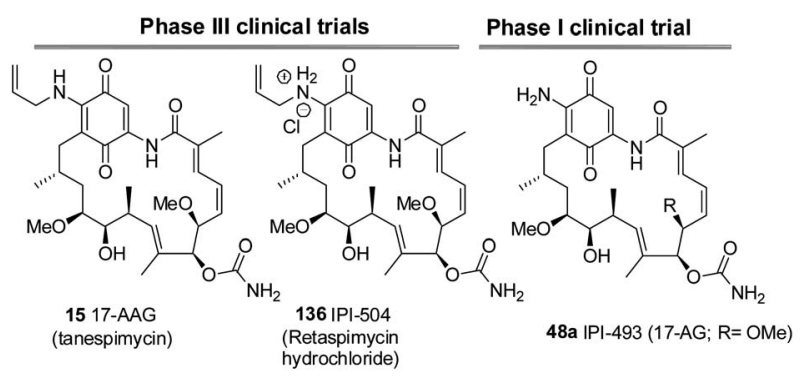

Radicicol (13) as lead structure

Phase II clinical trial Phase I/II clinical trial Phase II/III clinical trial

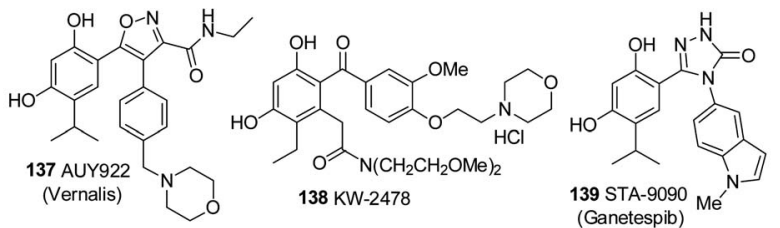

Fig. 19 Natural products-derived Hsp90 inhibitors currently in clinical trials against different cancers (status October 2012).

These studies indicate that Hsp90 and Hsp70 have roles in human immune response and Hsp90 may promote the stability of oligomeric Tau and $\beta$-amyloid peptides, thought to be toxic species involved in the pathology of Alzheimer's disease. Cancer selective responses in Hsp expression and their clients will therefore require a fine adjustment in combinatorial therapies (see also Fig. 2). ${ }^{\mathbf{1 1 7}}$ A putative answer to the cancer expression barcode could be a combinatorial set of different ansamycin derivatives synthesised, as shown recently, and desirably tested on commercially available Hsp microarrays. ${ }^{123}$

Undoubtedly, this decade will answer the question of whether Hsp90 is a druggable target, especially in cancer therapy.

\section{Acknowledgements}

Contributions from Hannover to this field of research were only possible by a group of creative and motivated co-workers. Particular thanks we owe to Dr F. Taft and J. Hermane. Excellence in the NMR (Dr J. Fohrer) and MS departments (Dr Dräger) are gratefully acknowledged. Biological testing was performed by F. Sasse (Helmholtz center of infection Research; HZI, Braunschweig, Germany). We are particularly grateful to H. G. Floss (University of Washington, Seattle, USA) for initial and continuous generous support. Finally, we thank the Fonds der Chemischen Industrie, the Deutsche Forschungsgemeinschaft (grant Ki 397/7-1 and Ki 397/13-1) and the Leibniz University (ZE WiF I, 2008; WiF II 2009) for financial contributions.

\section{Notes and references}

1 F. Bray, A. Jemal, N. Grey, J. Ferlay and D. Forman, Lancet Oncol., 2012, 13, 790-801.
2 (a) M. Ferrarini, S. Heltai, M. R. Zocchi and C. Rugarli, Int. J. Cancer, 1992, 19, 613-619; (b) Y. Xu and S. Lindquist, Proc. Natl. Acad. Sci. U. S. A., 1993, 90, 7074-7078.

3 (a) R. S. Gupta, Mol. Biol. Evol., 1995, 12, 1063-1073; (b) J. Robert, Dev. Comp. Immunol., 2003, 27, 449-464.

4 Y. Fukuyo, C. Hunt and N. Horikoshi, Cancer Lett., 2010, 290, 24-35.

5 (a) M. Gorska, Front. Biosci., 2012, 17, 2267-2277; (b) J. R. Porter, J. E. Ge, J. Lee, E. Normant and K. West, Curr. Top. Med. Chem., 2009, 9, 1386-1418.

6 (a) P. Stead, S. Latif, A. P. Blackaby, P. J. Sidebottom, A. Deakin, N. L. Taylor, P. Life, J. Spaull, F. Burrell, R. Jones, J. Lewis, I. Davidson and T. Mander, J. Antibiot., 2000, 53, 657-663; (b) M. G. Li, S. H. Wu, L. X. Zhao, Q. Zhang, W. J. Li, X. L. Cui, L. H. Xu, D. G. Wu and C. L. Jiang, Chin. Chem. Lett., 2001, 12, 903-906; (c) S. Li, S. Ni, L. Wu, L. Li, B. Jiang, H. Wang, G. Sun, M. Gan, J. Li, W. He, L. Lin, Y. Wang, S. Bai and S. Si, J. Nat. Prod., 2013, 76(5), 969-973; (d) X. Liu, J. Li, S. Ni, L. Wu, H. Wang, L. Lin, W. He and Y. Wang, J. Antibiot., 2011, 64, 519-522; (e) L. Lin, S. Ni, L. Wu, Y. Wang, Y. Wang, P. Tao, W. He and X. Wang, Biosci., Biotechnol., Biochem., 2011, 75, 2042-2045.

7 (a) K. L. Rinehart, K. Sasaki, G. Slomp, M. F. Grostic and E. C. Olson, J. Am. Chem. Soc., 1970, 92, 7591; (b) L. H. Li, T. D. Clark, C. H. Cowie and K. L. Rinehart, Jr., Cancer Treat. Rep., 1977, 61, 815-824.

8 H. J. Patel, S. Modi, G. Chiosis and T. Taldone, Expert Opin. Drug Discovery, 2011, 6, 559-587.

9 (a) B. Chen, D. Zhong and A. Monteiro, BMC Genomics, 2006, 7, 156; (b) M. Taipale, D. F. Jarosz and S. Lindquist, Nat. Rev. Mol. Cell Biol., 2010, 11, 515-528.

10 H. H. Kampinga, J. Hageman, M. J. Vos, H. Kubota, R. M. Tanguay, E. A. Bruford, Cheetham, B. Chen and L. E. Hightower, Cell Stress Chaperones, 2009, 14, 105-111.

11 (a) L. H. Pearl and C. Prodromou, Curr. Opin. Struct. Biol., 2000, 10, 46-51; (b) L. H. Pearl and C. Prodromou, Adv. Protein Chem., 2001, 59, 157-186; (c) C. Prodromou and L. H. Pearl, Curr. Cancer Drug Targets, 2003, 3, 301-323.

12 K. A. Krukenberg, T. O. Street, L. A. Lavery and D. A. Agard, Q. Rev. Biophys., 2011, 44, 229-255.

13 (a) B. Snel, G. Lehmann, P. Bork and M. A. Huynen, Nucleic Acids Res., 2000, 28, 3442-3444; (b) A. Franceschini, D. Szklarczyk, S. Frankild, M. Kuhn, M. Simonovic, A. Roth, J. Lin, P. Minguez, P. Bork, C. von Mering and L. J. Jensen, Nucleic Acids Res., 2013, 41, 808-815; (c) P. C. Echeverría, A. Bernthaler, P. Dupuis, B. Mayer and D. Picard, PLoS One, 2011, 6, 1-11.

14 (a) M. Taipale, I. Krykbaeva, M. Koeva, C. Kayatekin, K. D. Westover, G. I. Karras and S. Lindquist, Cell, 2012, 150, 987-1001; (b) P. Aloy and R. B. Russell, FEBS Lett., 2002, 530, 253-254.

15 M. W. Amolins and B. S. Blagg, Mini-Rev. Med. Chem., 2009, 9, 140-152.

16 (a) A. K. McCollum, C. J. TenEyck, B. Stensgard, B. W. Morlan, K. V. Ballman, R. B. Jenkins, D. O. Toft and C. Erlichman, Cancer Res., 2008, 68, 7419-7427; (b) 
L. Whitesell and N. U. Lin, Biochim. Biophys. Acta, Mol. Cell Res., 2012, 1823, 756-766.

17 (a) G. Marcu, A. Chadli, I. Bouhouche, M. Catelli and L. M. Neckers, J. Biol. Chem., 2000, 275, 37181-37186; (b) M. G. Marcu, T. W. Schulte and L. Neckers, J. Natl. Cancer Inst., 2000, 92, 242-248.

18 M. M. U. Ali, S. M. Roe, C. Vaughan, P. Meyer, B. Panaretou, P. W. Piper, C. Prodromou and L. H. Pearl, Nature, 2006, 440, 1013-1017.

19 (a) S. Lindquist, Cold Spring Harbor Symp. Quant. Biol., 2009, 74, 103-108; (b) G. Chen, W. D. Bradford, C. W. Seidel and R. Li, Nature, 2012, 482, 246-250.

20 (a) C. Jolly and R. I. Morimoto, J. Natl. Cancer Inst., 2000, 92, 1564-1572; (b) D. A. Parsell and S. Lindquist, Annu. Rev. Genet., 1993, 27, 437-496; (c) R. I. Morimoto, M. P. Kline, D. N. Bimston and J. J. Cotto, Essays Biochem., 1997, 32, 17-29; (d) G. Crevel, H. Bates, H. Huikeshoven and S. Cotterill, J. Cell Science, 2001, 114, 2015-2025; (e) L. Neckers, Trends Mol. Med., 2002, 8, S55-61; (f) L. Whitesell and S. L. Lindquist, Nat. Rev. Cancer, 2005, 5, 761-772.

21 (a) R. Zhao and W. A. Houry, Biochem. Cell Biol., 2005, 83, 703-710; $(b)$ R. F. de Zoeten, L. Wang, K. Butler, U. H. Beier, T. Akimova, H. Sai, J. E. Bradner, R. Mazitschek, A. P. Kozikowski, P. Matthias and W. W. Hancock, Mol. Cell. Biol., 2011, 31, 2066-2078.

22 (a) T. H. Davies, Y. M. Ning and E. R. Sánchez, J. Biol. Chem., 2002, 277, 4597-4600; (b) R. Hamamoto, Y. Furukawa, M. Morita, Y. Iimura, F. P. Silva, M. Li, R. Yagyu and Y. Nakamura, Nat. Cell Biol., 2004, 6, 731-740.

23 (a) O. A. Toogun, D. C. Dezwaan and B. C. Freeman, Mol. Cell. Biol., 2008, 28, 457-467; (b) B. R. Keppler, A. T. Grady and M. B. Jarstfer, J. Biol. Chem., 2006, 281, 9840-19848; (c) R. Villa, M. Folini, C. D. Porta, A. Valentini, M. Pennati, M. G. Daidone and N. Zaffaroni, Carcinogenesis, 2003, 24, 851-859.

24 (a) F. U. Hartl, A. Bracher and M. Hayer-Hartl, Nature, 2011, 475, 324-332; (b) F. U. Hartl and M. Hayer-Hartl, Science, 2002, 295, 1852-1858.

25 J. G. Thomas and F. Baneyxm, J. Bacteriol., 1998, 180, 51655172.

26 (a) M. Tanabe, Y. Kawazoe, S. Takeda, R. I. Morimoto, K. Nagata and A. Nakai, EMBO J., 1998, 16, 1750-1758; (b) R. I. Morimoto, Genes Dev., 1998, 12, 3788-3796.

27 (a) X. Wang, M. A. Khaleque, M. J. Zhao, R. Zhong, M. Gaestel and S. K. Calderwood, J. Biol. Chem., 2006, 281, 782-791; (b) R. Baler, G. Dahl and R. Voellmy, Mol. Cell. Biol., 1993, 13, 2486-2496; (c) Y. Guo, T. Guettouche, M. Fenna, F. Boellmann, W. B. Pratt, D. O. Toft, D. F. Smith and R. Voellmy, J. Biol. Chem., 2001, 276, 45791-45799; (d) R. Bagatell, G. D. Paine-Murrieta, C. W. Taylor, E. J. Pulcini, S. Akinaga, I. J. Benjamin and L. Whitesell, Clin. Cancer Res., 2000, 6, 3312-3318; (e) C. Wu, Annu. Rev. Cell Dev. Biol., 1995, 11, 441-469.

28 L. Neckers, Curr. Med. Chem., 2003, 10, 733-739.

29 A. Rodriguez-Sinovas, K. Boengler, A. Cabestrero, P. Gres, M. Morente, M. Ruiz-Meana, I. Konietzka, E. Miró,
A. Totzeck, G. Heusch, R. Schulz and D. Garcia-Dorado, Circ. Res., 2006, 7, 93-101.

30 (a) M. A. Theodoraki and A. J. Caplan, Biochim. Biophys. Acta, Mol. Cell Res., 2012, 1823, 683-688; (b) P. N. Munster, A. Basso, D. Solit, L. Norton and N. Rosen, Clin. Cancer Res., 2001, 7, 2155-2158.

31 (a) R. Kumar, A. Musiyenko and S. Barik, Malar. J., 2003, 2, 1-11; (b) M. A. Morales, R. Watanabe, M. Dacher, P. Chafey, J. Osorio y Fortéa, D. A. Scott, S. M. Beverley, G. Ommen, J. Clos, S. Hem, P. Lenormand, J. C. Rousselle, A. Namane and G. F. Späth, Proc. Natl. Acad. Sci. U. S. A., 2010, 107, 8381-8386; (c) L. E. Cowen, PLoS Pathog., 2009, 5, e1000471; (d) G. Homuth, S. Domm, D. Kleiner and W. Schumann, J. Bacteriol., 2000, 182, 4257-4263; (e) R. Kumar, S. R. Pavithra and U. Tatu, J. Biosci., 2007, 32, 531-536.

32 A. Zuehlke and J. L. Johnson, Biopolymers, 2010, 93, 211-217. 33 (a) A. Granelli-Piperno, L. Andrus and R. M. Steinman, J. Exp. Med., 1986, 163, 922-937; (b) L. H. Pearl, C. Prodromou and P. Workman, Biochem. J., 2008, 410, 439-453.

34 L. H. Pearl and C. Prodromou, Annu. Rev. Biochem., 2006, 75, 271-294.

35 A. K. Shiau, S. F. Harris, D. R. Southworth and D. A. Agard, Cell, 2006, 127, 329-340.

36 S. H. McLaughlin, L. A. Ventouras, B. Lobbezoo and S. E. Jackson, J. Mol. Biol., 2004, 344, 813-826.

37 C. Ratzke, F. Berkemeier and T. Hugel, Proc. Natl. Acad. Sci. U. S. A., 2012, 109, 161-16.

38 C. Ratzke, M. Mickler, B. Hellenkamp, J. Buchner and T. Hugel, Proc. Natl. Acad. Sci. U. S. A., 2010, 107, 1610116106.

39 D. R. Southworth and D. A. Agard, Mol. Cell, 2008, 32, 631640.

40 T. Makhnevych and W. A. Houry, Biochim. Biophys. Acta, Mol. Cell Res., 2012, 1823, 674-682.

41 J. L. Johnson and C. Brown, Cell Stress Chaperones, 2009, 14, 83-94.

42 D. R. Southworth and D. A. Agard, Mol. Cell, 2011, 42, 771781.

43 M. Retzlaff, F. Hagn, L. Mitschke, M. Hessling, F. Gugel, H. Kessler, K. Richter and J. Buchner, Mol. Cell, 2010, 37, 344-354.

44 (a) S. Chen and D. F. Smith, J. Biol. Chem., 1998, 273, 3519435200; (b) C. Scheufler, A. Brinker, G. Bourenkov, S. Pegoraro, L. Moroder, H. Bartunik, F. U. Hartl and I. Moarefi, Cell, 2000, 101, 199-210.

45 J. C. Young, I. Moarefi and F. U. Hartl, J. Cell Biol., 2001, 154, 267-273.

46 W. B. Pratt and K. D. Dittmar, Trends Endocrinol. Metab., 1998, 9, 254-252.

47 A. Citri, D. Harari, G. Shohat, P. Ramakrishnan, J. Gan, S. Lavi, M. Eisenstein, A. Kimchi, D. Wallach, S. Pietrokovski and Y. Yarden, J. Biol. Chem., 2006, 281, 14361-14369.

48 N. V. Marozkina, S. Yemen, M. Borowitz, L. Liu, M. Plapp, F. Sun, R. Islam, P. Erdmann-Gilmore, R. R. Townsend, 
C. F. Lichti, S. Mantri, P. W. Clapp, S. H. Randell, B. Gaston and K. Zaman, Proc. Natl. Acad. Sci. U. S. A., 2010, 107, 11393-11398.

49 J. Li, J. Soroka and J. Buchner, Biochim. Biophys. Acta, Mol. Cell Res., 2012, 1823, 624-635.

50 H. Ogiso, N. Kagi, E. Matsumoto, M. Nishimoto, R. Arai, M. Shirouzu, J. Mimura, Y. Fujii-Kuriyama and S. Yokoyama, Biochemistry, 2004, 43, 15510-15519.

51 (a) M. Mollapour and L. Neckers, Methods Mol. Biol., 2011, 787, 67-74; (b) Y. Miyata, Cell. Mol. Life Sci., 2009, 66, 1840-1849.

52 B. T. Scroggins, K. Robzyk, D. Wang, M. G. Marcu, S. Tsutsumi, K. Beebe, R. J. Cotter, S. Felts, D. Toft, L. Karnitz, N. Rosen and L. Neckers, Mol. Cell, 2007, 25, 151-159.

53 M. Retzlaff, M. Stahl, H. C. Eberl, S. Lagleder, J. Beck, H. Kessler and J. Buchner, EMBO Rep., 2009, 10, 11471153.

54 (a) R. Hamamoto, Y. Furukawa, M. Morita, Y. Iimura, F. P. Silva, M. Li, R. Yagyu and Y. Nakamura, Nat. Cell Biol., 2004, 6, 731-740; (b) R. Hamamoto, F. P. Silva, M. Tsuge, T. Nishidate, T. Katagiri, Y. Nakamura and Y. Furukawa, Cancer Sci., 2006, 97, 113-118.

55 S. J. Park, B. N. Borin, M. A. Martinez-Yamout and H. J. Dyson, Nat. Struct. Mol. Biol., 2011, 18, 537-541.

56 (a) J. S. Hahn, BMB Rep., 2009, 42, 623-630; (b) W. Luo, W. Sun, T. Taldone, A. Rodina and G. Chiosis, Mol. Neurodegener., 2010, 5, 1-8.

57 (a) L. Neckers, J. Biosci., 2007, 32, 517-530; (b) H. Yamaki, M. Nakajima, K. W. Shimotohno and N. Tanaka, J. Antibiot., 2011, 64, 635-644.

58 K. Moulick, J. H. Ahn, H. Zong, A. Rodina, L. Cerchietti, E. M. Gomes DaGama, E. Caldas-Lopes, K. Beebe, F. Perna, K. Hatzi, L. P. Vu, X. Zhao, D. Zatorska, T. Taldone, P. Smith-Jones, M. Alpaugh, S. S. Gross, N. Pillarsetty, T. Ku, J. S. Lewis, S. M. Larson, R. Levine, H. Erdjument-Bromage, M. L. Guzman, S. D. Nimer, A. Melnick, L. Neckers and G. Chiosis, Nat. Chem. Biol., 2011, 7, 818-826.

59 X. Yu, Z. S. Guo, M. G. Marcu, L. Neckers, D. M. Nguyen, G. A. Chen and D. S. Schrump, J. Natl. Cancer Inst., 2002, 94, 504-513.

60 (a) L. Müller, A. Schaupp, D. Walerych, H. Wegele and J. Buchner, J. Biol. Chem., 2004, 279, 48846-48854; (b) M. V. Blagosklonny, J. Toretsky, S. Bohen and L. Neckers, Proc. Natl. Acad. Sci. U. S. A., 1996, 93, 8379-8383.

61 M. Ferrarini, S. Heltai, M. R. Zocchi and C. Rugarli, Int. J. Cancer, 1992, 51, 613-619.

62 (a) A. Maloney, P. A. Clarke and P. Workman, Curr. Cancer Drug Targets, 2003, 3, 331-341; (b) P. Workman, Trends Mol. Med., 2004, 10, 47-51.

63 C. E. Stebbins, A. A. Russo, C. Schneider, N. Rosen, F. U. Hartl and N. P. Pavletich, Cell, 1997, 89, 239-250.

64 Y. Li, G. I. Karagöz, Y. H. Seo, T. Zhang, Y. Jiang, Y. Yu, A. M. S. Duarte, S. J. Schwartz, R. Boelens, K. Caroll, S. G. D. Rüdiger and D. Sun, J. Nutr. Biochem., 2012, 23, 1617-1626.
65 J. Li, L. Sun, C. Xu, F. Yu, H. Zhou, Y. Zhao, J. Zhang, J. Cai, C. Mao, L. Tang, Y. Xu and J. He, Acta Biochim. Biophys. Sin., 2012, 44, 300-306.

66 C. E. Stebbins, A. A. Russo, C. Schneider, N. Rosen, F. U. Hartl and N. P. Pavletich, Cell, 1997, 89, 239-250.

67 J. M. Jez, J. C. Chen, G. Rastelli, R. M. Stroud and D. V. Santi, Chem. Biol., 2003, 10, 361-368.

68 (a) M. A. Biamonte, R. Van de Water, J. W. Arndt, R. H. Scannevin, D. Perret and W.-C. Lee, J. Med. Chem., 2010, 53, 3-17; (b) Y. L. Janin, J. Med. Chem., 2005, 48, $7503-7512$.

69 (a) K. D. Corbett and J. M. Berger, Proteins: Struct., Funct., Bioinf., 2010, 78, 2738-2744; (b) R. Pallavi, N. Roy, R. K. Nageshan, P. Talukdar, S. R. Pavithra, R. Reddy, S. Venketesh, R. Kumar, A. K. Gupta, R. K. Singh, S. C. Yadav and U. Tatu, J. Biol. Chem., 2010, 285, 3796437975; (c) A. L. Petersen, C. E. Guedes, C. L. Versoza, J. G. Lima, L. A. de Freitas, V. M. Borges and P. S. Veras, PLoS One, 2012, 7, e49496.

70 (a) R. L. Cysyk, R. J. Parker, J. J. Barchi, Jr., P. S. Steeg, N. R. Hartmann and J. M. Strong, Chem. Res. Toxicol., 2006, 19, 376-381.

71 P. Meyer, C. Prodromou, B. Hu, C. Vaughan, S. M. Roe, B. Panaretou, P. W. Piper and L. H. Pearl, Mol. Cell, 2003, 11, 647-658.

72 L. H. Pearl, C. Prodromou and P. Workman, Biochem. J., 2008, 410, 439-453.

73 J. Trepel, M. Mollapour, G. Giaccone and L. Neckers, Nat. Rev. Cancer, 2010, 10, 537-549.

74 F. Yi and L. Regan, ACS Chem. Biol., 2008, 3, 645-654.

75 M. G. Marcu, A. Chadli, I. Bouhouche, M. Catelli and L. M. Neckers, J. Biol. Chem., 2000, 275, 37181-37186.

76 M. G. Marcu, T. W. Schulte and L. Neckers, J. Natl. Cancer Inst., 2000, 92, 242-248.

77 C. M. Palermo, C. A. Westlake and T. A Gasiewicz, Biochemistry, 2005, 44, 5041-5052.

78 (a) M. Q. Zhang and B. Wilkinson, Curr. Opin. Biotechnol., 2007, 18, 478-488; (b) F. von Nussbaum, M. Brands, B. Hinzen, S. Weigand and D. Häbich, Angew. Chem., 2006, 118, 5194-5254; Angew. Chem., Int. Ed., 2006, 45, 5072; (c) I. Paterson and E. A. Anderson, Science, 2005, 310, 451-453; (d) D. J. Newman, G. M. Cragg and K. M. Snader, J. Nat. Prod., 2003, 66, 1022-1037.

79 J. Rohr, Angew. Chem., Int. Ed. Engl., 1995, 34, 881-888; Angew. Chem., 1995, 107, 963.

80 (a) S. Weist and R. D. Süssmuth, Appl. Microbiol. Biotechnol., 2005, 68, 141-150; (b) A. Kirschning, F. Taft and T. Knobloch, Org. Biomol. Chem., 2007, 5, 3245-3295.

81 (a) M.-C. Wu, B. Law, B. Wilkinson and J. Micklefield, Curr. Opin. Biotechnol., 2012, 23, 931-940; (b) R. J. M. Goss, S. Shankar and A. A. Fayad, Nat. Prod. Rep., 2012, 29, 870889; (c) K. Weisman, Trends Biotechnol., 2007, 25, 139-42.

82 The first time, this concept was mentioned by (a) A. J. Birch, Pure Appl. Chem., 1963, 7, 527-537; in a later paper this concept was further specified: (b) W. T. Shier, K. L. Rinehart Jr. and D. Gottlieb, Proc. Natl. Acad. Sci. U. S. A., 1969, 63, 198-204. 
83 A. Kirschning and F. Hahn, Angew. Chem., 2012, 124, 40864096; Angew. Chem., Int. Ed., 2012, 51, 4012.

84 I. Sattler, R. Thiericke and S. Grabley in Drug Discovery from Nature, ed. S. Grabley and R. Thiericke, Springer Verlag, Berlin, Heidelberg, 1999, ch. 11, pp. 191-214.

85 M. Nakata, T. Osumi, A. Ueno, T. Kimura, T. Tamai and K. Tatsuta, Tetrahedron Lett., 1991, 32, 6015-6018.

86 (a) M. B. Andrus, E. L. Meredith, B. L. Simmons, B. B. V. Soma Sekkar and E. J. Hicken, Org. Lett., 2002, 4, 3549-3552; (b) M. B. Andrus, E. J. Hicken, E. L. Meredith, B. L. Simmons and J. F. Canon, Org. Lett., 2003, 5, 3859-3862.

87 H. Qin and J. S. Panek, Org. Lett., 2008, 10, 2477-2479.

88 H. Huang and J. S. Panek, J. Am. Chem. Soc., 2000, 122, 9836-9837 (different proposals for the transition state are discussed in ref. 87 and 88 ).

89 (a) I. E. Wrona, A. Gozman, T. Taldone, G. Chiosis and J. S. Panek, J. Org. Chem., 2010, 75, 2820-2835; (b) I. E. Wrona, A. E. Gabarda, G. Evano and J. S. Panek, J. Am. Chem. Soc., 2005, 127, 15026-15027.

90 T. Hampel, T. Neubauer, T. van Leeuwen and T. Bach, Chem.-Eur. J., 2012, 18, 10382-10392.

91 M. B. Andrus, Y. Wong, J. Liu, K. Beebe and L. M. Neckers, Tetrahedron Lett., 2009, 50, 6705-6708.

92 L. Rinehart Jr., M. W. McMillan, T. R. Witty, C. D. Tipton and L. S. Shield, Bioorg. Chem., 1977, 6, 353-369.

93 K. L. Rinehart Jr., W. Sobiczewski, J. F. Honegger, R. M. Enanoza, T. R. Witty, V. J. Lee and L. S. Shield, Bioorg. Chem., 1977, 6, 341-351.

94 R. C. Schnur and M. L. Corman, J. Org. Chem., 1994, 59, 2581-2584.

95 R. C. Schnur, M. L. Corman, R. J. Gallaschun, B. A. Cooper, M. F. Dee, J. L. Doty, M. L. Muzzi, J. D. Moyer, C. I. DiOrio, E. G. Barbacci, P. E. Miller, A. T. O'Brien, M. J. Morin, B. A. Foster, V. A. Pollack, D. M. Savage, D. E. Sloan, L. R. Pustilnik and M. P. Moyer, J. Med. Chem., 1995, 38, 3806-3812.

96 (a) E. A. Sausville, J. E. Tomaszewski and P. Ivy, Curr. Cancer Drug Targets, 2003, 3, 377-383; (b) U. Banerji, A. O'Donnell, M. Scurr, S. Pacey, S. Stapleton, Y. Asad, L. Simmons, A. Maloney, F. Raynaud, M. Campbell, M. Walton, S. Lakhani, S. Kaye, P. Workman and I. Judson, J. Clin. Oncol., 2005, 23, 4152-4161; (c) R. K. Ramanathan, D. L. Trump, J. L. Eiseman, C. P. Belani, S. S. Agarwala, E. G. Zuhowski, J. Lan, D. M. Potter, S. P. Ivy, S. Ramalingam, A. M. Brufsky, M. K. K. Wong, S. Tutchko and M. J. Egorin, Clin. Cancer Res., 2005, 11, 3385-3391; (d) M. P. Goetz, D. Toft, J. Reid, M. Ames, B. Stensgard, S. Safgren, A. A. Adjei, J. Sloan, J. Atherton, P. Vasile, V. Salazaar, S. Adjei, A. Croghan and G. Erlichman, J. Clin. Oncol., 2005, 23, 1078-1087.

97 J.-Y. Le Brazidec, A. Kamal, D. Busch, L. Thao, L. Zhang, G. Timony, R. Grecko, K. Trent, R. Lough, T. Salazar, S. Khan, F. Burrows and M. F. Boehm, J. Med. Chem., 2004, 47, 3865-3873.

98 Z.-Q. Tian, Y. Liu, D. Zhang, Z. Wang, S. D. Dong, C. W. Carreras, Y. Zhou, G. Rastelli, D. V. Santi and D. C. Myles, Bioorg. Med. Chem., 2004, 12, 5317-5329.
99 J. Ge, E. Normant, J. R. Porter, J. A. Ali, M. S. Dembski, Y. Gao, A. T. Georges, L. Grenier, R. H. Pak, J. Patterson, J. R. Sydor, T. T. Tibbitts, J. K. Tong, J. Adams and V. J. Palombella, J. Med. Chem., 2006, 49, 4606-4615.

100 R. C. Clevenger, J. M. Raibel, A. M. Peck and B. S. J. Blagg, J. Org. Chem., 2004, 69, 4375-4380.

101 F. Wuest, V. Bouvet, B. Mai and P. LaPointe, Org. Biomol. Chem., 2012, 10, 6724-6731.

102 L. Fang, R. F. Battisti, H. Cheng, P. Reigan, Y. Xin, J. Shen, D. Ross, K. K. Chan, E. W. Martin Jr., P. G. Wang and D. Sun, J. Med. Chem., 2006, 49, 6290-6297.

103 H. Cheng, X. Cao, M. Xian, L. Fang, T. B. Cai, J. J. Ji, J. B. Tunac, D. Sun and P. G. Wang, J. Med. Chem., 2005, 48, 645-652.

104 (a) R. C. Schnur, M. L. Corman, R. J. Gallaschun, B. A. Cooper, M. F. Dee, J. L. Doty, M. L. Muzzi, C. I. DiOrio, E. G. Barbacci, P. E. Miller, V. A. Pollack, D. M. Savage, D. E. Sloan, L. R. Pustilnik, J. D. Moyer and M. P. Moyer, J. Med. Chem., 1995, 38, 3813-3820; (b) C. W. Zapf, J. D. Bloom, Z. Li, R. G. Dushin, T. Nittoli, M. Otteng, A. Nikitenko, J. M. Golas, H. Liu, J. Lucas, F. Boschelli, E. Vogan, A. Olland, M. Johnson and J. I. Levin, Bioorg. Med. Chem. Lett., 2011, 21, 4602-4607; (c) S. H. Millson, C. S. Chua, S. M. Roe, S. Polier, S. Solovieva, L. H. Pearl, T. S. Sim, C. Prodromou and P. W. Piper, FASEB J., 2011, 25, 3828-3837; (d) P. W. Piper and S. H. Millson, Open Biol., 2012, 2, 120138.

105 G. Rastelli, Z.-Q. Tian, Z. Wang, D. Myles and Y. Liu, Bioorg. Med. Chem. Lett., 2005, 15, 5016-5021.

106 (a) C.-G. Kim, T. W. Yu, C. B. Fryhle, S. Handa and H. G. Floss, J. Biol. Chem., 1997, 11, 6030-6040; (b) K. Arakawa, R. Müller, T. Mahmud, T.-W. Yu and H. G. Floss, J. Am. Chem. Soc., 2002, 124, 10644-10645.

107 For biosynthetic details of geldanamycin see (a) A. Rascher, Z. Hu, N. Viswanathan, A. Schirmer, R. Reid, W. C. Nierman, M. Lewis and C. R. Hutchinson, FEMS Microbiol. Lett., 2003, 218, 223-230; (b) A. Rascher, Z. Hu, G. O. Buchanan, R. Reid and C. R. Hutchinson, Appl. Environ. Microbiol., 2005, 71, 4862-4871; (c) Y.-S. Hong, D. Lee, W. Kim, J. K. Jeong, C. G. Kim, J. K. Sohng, J. H. Lee, S. G. Paik and J. J. Lee, J. Am. Chem. Soc., 2004, 126, 11142-11143; (d) D. Lee, K. Lee, X. F. Cai, N. T. Dat, S. K. Boovanahalli, M. Lee, J. C. Shin, W. Kim, J. K. Jeong, J. S. Lee, C. H. Lee, J. H. Lee, Y.-S. Hong and J. J. Lee, ChemBioChem, 2006, 7, 246-248.

108 K. Patel, M. Piagentini, A. Rascher, Z. Q. Tian, G. O. Buchanan, R. Regentin, Z. Hu, C. R. Hutchinson and R. McDaniel, Chem. Biol., 2004, 11, 1625-1633.

109 T. Schwecke, J. F. Aparicio, I. Molnar, A. König, L. E. Khaw, S. F. Haydock, M. Oliynyk, P. Caffrey, J. Cortes, J. B. Lester, G. A. Böhm, J. Staunton and P. F. Leadlay, Proc. Natl. Acad. Sci. U. S. A., 1995, 92, 7839-7843.

110 M. Q. Zhang, S. Gaisser, M. Nur-E-Alam, L. S. Sheehan, W. A. Vousden, N. Gaitatzis, G. Peck, N. J. Coates, S. J. Moss, M. Radzom, T. A. Foster, R. M. Sheridan, M. A. Gregory, S. M. Roe, C. Prodromou, L. Pearl, 
S. M. Boyd, B. Wilkinson and C. J. Martin, J. Med. Chem., 2008, 51, 5494-4947.

111 W. Kim, D. Lee, S. S. Hong, Z. Na, J. C. Shin, S. H. Roh, C. Z. Wu, O. Choi, K. Lee, Y. M. Shen, S. G. Paik, J. J. Lee and Y. S. Hong, ChemBioChem, 2009, 10, 1243-1251.

112 K. Lee, J. S. Ryn, Y. Jin, W. Kim, N. Kaur, S. J. Chung, Y.-J. Jeon, J.-T. Park, J. S. Bang, H. S. Lee, T. Y. Kim, J. J. Lee and Y.-S. Hong, Org. Biomol. Chem., 2008, 6, 340348.

113 (a) H. G. Menzella, T.-T. Tran, J. R. Carney, J. Lau-Wee, J. Galazzo, C. D. Reeves, C. Carreras, S. Mukadam, S. Eng, Z. Zhong, P. B. W. M. Timmermans, S. Murli and G. W. Ashley, J. Med. Chem., 2009, 52, 1518-1521; (b) G. W. Ashley, J. R. Carney, H. Menzella and J. LauWee, PCT Int. Appl., 2008, p. 53, Pub. No.: US 2008/ 0188450 A1.

114 W. Kim, J. S. Lee, D. Lee, X. F. Cai, J. C. Shin, K. Lee, C.-H. Lee, S. Ryu, S.-G. Paik, J. J. Lee and Y.-S. Hong, ChemBioChem, 2007, 8, 1491-1494.

115 W. Kim, D. Lee, S. S. Lee, Z. Na, J. C. Shin, S. H. Roh, C.-Z. Wu, O. Choi, K. Lee, Y.-M. Shen, S.-G. Paik, J. J. Lee and Y.-S. Hong, ChemBioChem, 2009, 10, 1243-1251.

116 S. Eichner, H. G. Floss, F. Sasse and A. Kirschning, ChemBioChem, 2009, 10, 1801-1805.

117 S. Eichner, T. Eichner, H. G. Floss, J. Fohrer, E. Hofer, F. Sasse, C. Zeilinger and A. Kirschning, J. Am. Chem. Soc., 2012, 134, 1673-1679.
118 L. Galam, M. K. Hadden, Z. Ma, Q. Z. Ye, B. G. Yun, B. S. Blagg and R. L. Matts, Bioorg. Med. Chem., 2007, 15, 1939-1946.

119 (a) R. L. Matts, G. E. Brandt, Y. Lu, A. Dixit, M. Mollapourm, S. Wang, A. C. Donnelly, L. Neckers, G. Verkhivker and B. S. Blagg, Bioorg. Med. Chem., 2011, 19, 684-692; (b) R. L. Matts, A. Dixit, L. B. Peterson, L. Sun, S. Voruganti, P. Kalyanaraman, S. D. Hartson, G. M. Verkhivker and B. S. Blagg, ACS Chem. Biol., 2011, 6, 800-807; (c) R. L. Matts and J. R. Manjarrez, Curr. Top. Med. Chem., 2009, 9, 1462-1478.

120 M. W. Amolins and B. S. Blagg, Mini-Rev. Med. Chem., 2009, 9, 140-152.

121 (a) W. Aherne, A. Maloney, C. Prodromou, M. G. Rowlands, A. Hardcastle, K. Boxall, P. Clarke, M. I. Walton, L. Pearl and P. Workman, Methods Mol. Med., 2003, 85, 149-161; (b) C. Austin, S. N. Pettit, S. K. Magnolo, J. Sanvoisin, W. Chen, S. P. Wood, L. D. Freeman, R. J. Pengelly and D. E. Hughes, J. Biomol. Screening, 2012, 17, 868-876; (c) S. A. Seidel, P. M. Dijkman, W. A. Lea, G. van den Bogaart, M. Jerabek-Willemsen, A. Lazic, J. S. Joseph, P. Srinivasan, P. Baaske, A. Simeonov, I. Katritch, F. A. Melo, J. E. Ladbury, G. Schreiber, A. Watts, D. Braun, S. Duhr, 2013, http://dx.doi.org/10.1016/j.ymeth.2012.12.005.

122 G. Chiosis, C. A. Dickey and J. L. Johnson, Nat. Struct. Mol. Biol., 2013, 20, 1-4.

123 C. Zeilinger and F. Stahl, unpublished results. 